Subscriber access provided by Caltech Library

\title{
Article
}

\section{An Operando Investigation of (Ni-Fe-Co-Ce)Ox System as Highly Efficient Electrocatalyst for Oxygen Evolution Reaction}

Marco Favaro, Walter S. Drisdell, Matthew A. Marcus, John

M. Gregoire, Ethan J. Crumlin, Joel A. Haber, and Junko Yano

ACS Catal., Just Accepted Manuscript • DOI: 10.1021/acscatal.6b03126 • Publication Date (Web): 27 Dec 2016

Downloaded from http://pubs.acs.org on January 3, 2017

\section{Just Accepted}

"Just Accepted" manuscripts have been peer-reviewed and accepted for publication. They are posted online prior to technical editing, formatting for publication and author proofing. The American Chemical Society provides "Just Accepted" as a free service to the research community to expedite the dissemination of scientific material as soon as possible after acceptance. "Just Accepted" manuscripts appear in full in PDF format accompanied by an HTML abstract. "Just Accepted" manuscripts have been fully peer reviewed, but should not be considered the official version of record. They are accessible to all readers and citable by the Digital Object Identifier (DOI®). "Just Accepted" is an optional service offered to authors. Therefore, the "Just Accepted" Web site may not include all articles that will be published in the journal. After a manuscript is technically edited and formatted, it will be removed from the "Just Accepted" Web site and published as an ASAP article. Note that technical editing may introduce minor changes to the manuscript text and/or graphics which could affect content, and all legal disclaimers and ethical guidelines that apply to the journal pertain. ACS cannot be held responsible for errors or consequences arising from the use of information contained in these "Just Accepted" manuscripts. 


\title{
An Operando Investigation of (Ni-Fe-Co-Ce) $\mathrm{O}_{x}$ System as Highly Efficient Electrocatalyst for Oxygen Evolution Reaction
}

\author{
Marco Favaro $\$ 1,2,3$, Walter S. Drisdell ${ }^{\ddagger 2,3}$, Matthew A. Marcus ${ }^{1}$, John M. Gregoire, ${ }^{4}$ Ethan J. Crumlin ${ }^{1, *}$, \\ Joel A. Haber, ${ }^{4, *}$, Junko Yano ${ }^{2,3,5, *}$
}

\begin{abstract}
${ }^{1}$ Advanced Light Source, Lawrence Berkeley National Laboratory, One Cyclotron Rd., Berkeley, CA 94720, USA.
2 Joint Center for Artificial Photosynthesis, Lawrence Berkeley National Laboratory, One Cyclotron Rd., Berkeley, CA 94720, USA.

${ }^{3}$ Chemical Sciences Division, Lawrence Berkeley National Laboratory, One Cyclotron Rd., Berkeley, CA 94720, USA.

${ }^{4}$ Joint Center for Artificial Photosynthesis, California Institute of Technology; Pasadena, CA 91125, USA.

${ }^{5}$ Molecular Biophysics and Integrated Bioimaging Division, Lawrence Berkeley National Laboratory, One Cyclotron Rd., Berkeley, CA 94720.
\end{abstract}

*Correspondence to: Ethan J. Crumlin (ejcrumlin@lbl.gov), Joel A. Haber (jahaber@caltech.edu) and Junko Yano (jyano@lbl.gov).

¥ These two authors equally contributed to the work.

\begin{abstract}
The oxygen evolution reaction (OER) is a critical component of industrial processes such as electrowinning of metals and the chlor-alkali process. It also plays a central role in the developing renewable energy field of solar-fuels generation by providing both the protons and electrons needed to generate fuels such as $\mathrm{H}_{2}$ or reduced hydrocarbons from $\mathrm{CO}_{2}$. To improve these processes, it is necessary to expand the fundamental understanding of catalytically active species at low overpotential, which will further the development of electrocatalysts with high activity and durability. In this context, performing experimental investigations of the electrocatalysts under realistic working regimes, i.e. under operando conditions, is of crucial importance. Here, we study a highly active quinary transition metal oxide-based OER electrocatalyst by means of operando ambient pressure X-ray photoelectron spectroscopy and X-ray absorption spectroscopy performed at the solid/liquid interface. We observe that the catalyst undergoes a clear chemical-structural evolution as a function of the applied potential with $\mathrm{Ni}$, Fe and Co oxyhydroxides comprising the active catalytic species. While $\mathrm{CeO}_{2}$ is redox inactive under catalytic conditions, its influence on the redox processes of the transition metals boosts the catalytic activity at low overpotentials, introducing an important design principle for the optimization of electrocatalysts and tailoring of high performance materials.
\end{abstract}

Keywords. Oxygen evolution reaction (OER), transiton metal oxides, operando techniques, ambient pressure, catalytic conditions, synchrotron radiation, electron spectroscopies.

\section{Introduction}

Discovering improved electrocatalysts for the oxygen evolution reaction (OER) is of great importance for sustainable energy conversion. ${ }^{1-3}$ Ascertaining structure-property relationships remains a central challenge in the field of heterogeneous catalysis and comprises an important strategy for the development of superior electrocatalysts. ${ }^{4-6}$ Enhanced catalytic activity has been 
ascribed to amorphous materials as heterogeneous catalysts and OER electrocatalysts, ${ }^{7-18}$ while high activity and stability has also been reported for nanostructured, multi-phase heterogeneous catalysts and electrocatalysts, with the behavior attributed to cooperative effects like spill-over or unique interfacial crystallographic structures. ${ }^{19-21}$ Among the most active and investigated OER electrocatalysts in basic electrolytes are transition metal oxy hydroxides. ${ }^{22-27}$ Their high activity is ascribed in part to volume activity of the hydrated catalyst. However, the role of adventitious iron contamination ${ }^{28-31}$ and their behavior as "adaptive junctions",32,33 i.e. the change in structure, oxidation, hydration, etc. when placed under operating potential, has confounded identification of activity trends of the transition metals, and of identification of the catalytically active metal centers. $^{34-36}$

We recently reported a high throughput investigation of the (Ni-Fe-Co-Ce) $\mathrm{O}_{\mathrm{x}}$ composition space which identified a new, unpredicted Ce-rich composition region of active OER electrocatalysts. ${ }^{37}$ Given the comparatively low activity of $\mathrm{CeO}_{\mathrm{x}}$, the high catalytic activity of the Ce-rich catalyst is quite surprising, motivating detailed study of this catalyst. Previous ex situ structural characterization of the $\mathrm{Ni}_{0.3} \mathrm{Fe}_{0.07} \mathrm{Co} 0.2 \mathrm{Ce}_{0.43} \mathrm{O}_{x}$ catalyst using both XAS and low-dose, high-resolution TEM demonstrated that the catalyst is a two-phase nanocomposite in which $\mathrm{CeO}_{2}$ nanoparticles form atomically sharp grain boundaries with alloyed transition metal oxides. ${ }^{38}$ While examination of the as-synthesized and post-operation catalyst revealed no significant changes to the structure or chemistry, ${ }^{38}$ understanding the catalytic activity enabled by the nanostructure requires detailed characterization under polarization (i.e. as a function of the applied potential), which is reported herein.

In $\mathrm{pH} 14$ electrolyte, $\mathrm{Ni}_{0.3} \mathrm{Fe}_{0.07} \mathrm{Co}_{0.2} \mathrm{Ce}_{0.43} \mathrm{O}_{x}$ exhibits comparable performance to optimal mixed-transition metal oxides at moderate overpotential and current density, in particular near 10 $\mathrm{mA} \mathrm{cm}{ }^{-2}$. At lower current density and overpotential, $\mathrm{Ni}_{0.3} \mathrm{Fe}_{0.07} \mathrm{Co}_{0.2} \mathrm{Ce}_{0.43} \mathrm{O}_{\mathrm{x}}$ outperforms all other catalysts in the $(\mathrm{Ni}-\mathrm{Fe}-\mathrm{Co}-\mathrm{Ce}) \mathrm{O}_{\mathrm{x}}$ composition space. This behavior can be represented in terms of the effective Tafel parameters, with the Ce-rich catalyst exhibiting twice the effective Tafel slope and orders of magnitude larger effective exchange current density than that of the previously reported $(\mathrm{Ni}-\mathrm{Fe}) \mathrm{O}_{\mathrm{x}}$ and $(\mathrm{Ni}-\mathrm{Co}) \mathrm{O}_{\mathrm{x}}$ catalysts. ${ }^{37,39}$ The effective Tafel behavior was found to correlate with the average redox potential in the mixed-metal oxide catalyst, which we further explore in the present work to elucidate the role of $\mathrm{Ce}$ in the quinary oxide catalyst.

$\mathrm{Ce}$ is well known as an oxygen reservoir in oxidation reactions because of its low redox potential, and is known to be a good oxygen-ion conductor with high surface-oxygen exchange density at elevated temperatures. ${ }^{40-45}$ Oxygen conductivity, surface-oxygen mobility and oxygen donation to co-catalysts are enhanced in nanostructured $\mathrm{CeO}_{2}$ and are mediated by grain boundaries and segregation of other cations therein. ${ }^{43,44}$ Recent work has capitalized on these unique properties of nanocrystalline $\mathrm{CeO}_{2}$ for enhancing the activity of $\mathrm{Pd}$ and Pt-based electrocatalysts for the oxygen reduction reaction (ORR), and detailed calculations have revealed the importance of oxygen spillover from ceria nanoparticles onto $\mathrm{Pt}^{46-52}$

The spillover of oxygen from $\mathrm{CeO}_{2}$ to the transition metal oxides in $\mathrm{Ni}_{0.3} \mathrm{Fe}_{0.07} \mathrm{Co}_{0.2} \mathrm{Ce}_{0.43} \mathrm{O}_{\mathrm{x}}$ could alter the transition metal species under operational conditions, motivating the examination 
of this catalyst with a suite of advanced in situ and operando X-ray spectroscopies. These recently-developed synchrotron techniques enable characterization of the potential-dependent oxidation states and chemical structures of electrocatalysts under realistic operating conditions. The methods have provided element-specific characterization of catalysts ${ }^{53,54}$ and illustrated the importance of collecting data under functional conditions. ${ }^{55-60}$ In the present work we advance the state-of-the-art of these techniques with the interrogation of the quinary oxide catalyst. We investigate the role of each transition metal-Ce oxide using two operando techniques (defined here as actively performing OER under potentiostatic control), ambient pressure X-ray photoelectron spectroscopy (APXPS) as a surface probe and X-ray absorption spectroscopy (XAS) as a bulk-probe. Combined information from these two techniques provides detailed insights of the location and the role of each metal oxide during OER electrocatalysis.

\section{Results and Discussion}

To identify the operating potentials of interest for operando characterization of the active electrocatalytic species, we first conduct a combinatorial investigation ${ }^{37,39}$ of the redox behavior in the (Ni-Fe-Co-Ce) $\mathrm{O}_{\mathrm{x}}$ system by acquiring cyclic voltammograms (CVs, aqueous $1 \mathrm{M} \mathrm{NaOH}$ electrolyte) for a series of catalyst compositions. ${ }^{37,39}$ The electrochemical current in each CV has contributions from capacitive charging, redox reactions of the electrocatalyst, and electrocatalysis, the last of which is relatively insensitive to the potential scan rate. To increase the relative signal from the redox reactions, we perform CVs at $0.25 \mathrm{~V} \mathrm{~s}^{-1}$ and sacrifice the observation of the onset of electrocatalytic activity, which was the focus of previous work. ${ }^{37}$ Given the ex situ segragation of $\mathrm{CeO}_{2}$ from the transition metal oxides, the behavior of $\mathrm{Ni}_{0.3} \mathrm{Fe}_{0.07} \mathrm{Co}_{0.2} \mathrm{Ce}_{0.43} \mathrm{O}_{\mathrm{x}}$ with respect to $\mathrm{Ni}-\mathrm{Fe}$ and $\mathrm{Ni}-\mathrm{Co}$ oxides is of particular interest, especially due to the previous reports on the active species in Ni-Fe and Co-based OER catalysts (see below). Figure 1 shows CVs for 18 metal oxide compositions that lie along 3 composition lines illustrated in Figure 1a. 

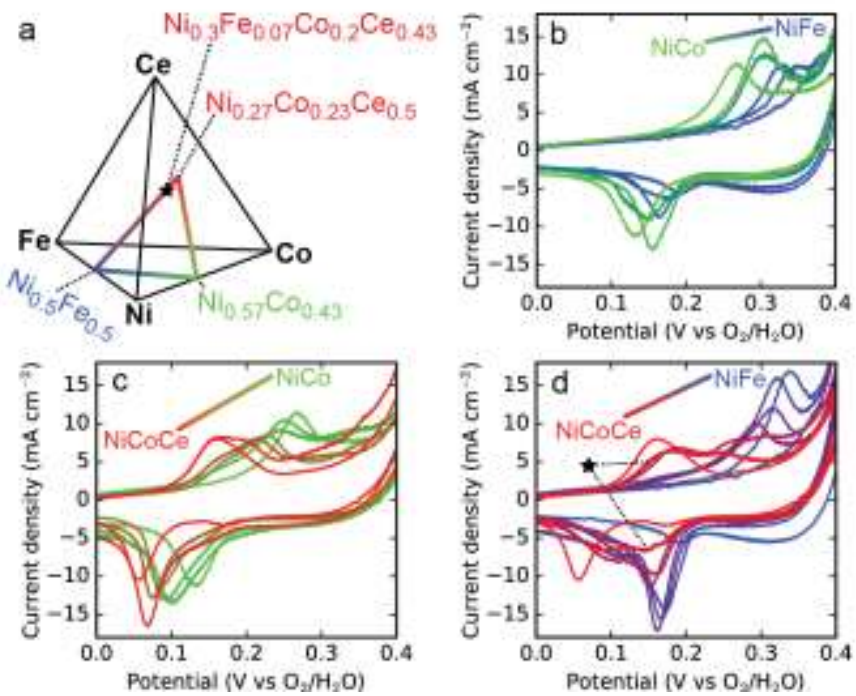

Figure 1. Color-coded composition lines in the Ni-Fe-Co-Ce oxide space (a) are shown with labelled end-point compositions. The catalyst redox regions of CVs acquired at $0.25 \mathrm{~V} \mathrm{~s}^{-1}$ are shown (b-d) for a series of compositions along each of the composition lines, with the $\mathrm{Ni}_{0.3} \mathrm{Fe}_{0.07} \mathrm{Co}_{0.2} \mathrm{Ce}_{0.43} \mathrm{O}_{\mathrm{x}}$ catalyst noted by a star in $\mathbf{a}$ and $\mathbf{d}$. The high current density from the non-catalytic processes obscure the onset of OER electrocatalysis. The composition of each catalyst is provided in Table $\mathbf{S} 1$.

Starting from $\mathrm{Ni} 0.5 \mathrm{Fe}_{0.5} \mathrm{O}_{\mathrm{x}}$ and extending to $\mathrm{Ni} 0.57 \mathrm{Co} 0.43 \mathrm{O}_{\mathrm{x}}$, Figure $\mathbf{1 b}$ shows that the catalyst redox processes systematically shift to lower potential, due in part to the removal of Fe which has been shown to increase the redox potential of $\mathrm{Ni}^{\text {(II/III) }}$. Figure $1 \mathrm{c}$ shows that the addition of $\mathrm{Ce}$ to $\mathrm{Ni}$-Co results in further decrease in redox potentials, thereby indicating a substantial influence of $\mathrm{Ce}$ on the redox processes of $\mathrm{Ni}$ and/or Co. Figure 1d covers the range of quinary oxide catalysts between the $\mathrm{Ni}-\mathrm{Fe}$ and $\mathrm{Ni}-\mathrm{Co}-\mathrm{Ce}$ end-members in Figures $\mathbf{1 b}$ and $\mathbf{1 c}$, which includes the $\mathrm{Ni} 0.3 \mathrm{Fe}_{0.07} \mathrm{Co}{ }_{2} \mathrm{Ce}_{0.43} \mathrm{O}_{x}$ catalyst, further illustrating that the addition of $\mathrm{Ce}$ to these transition metal oxides results in systematic lowering of redox potentials. For the quinary oxide catalysts in this series of CVs, there is a broad range of potentials over which redox activity is observed, likely due to overlapping signals from a variety of redox processes. In particular, inspection of the anodic sweep of the $\mathrm{Ni}_{0.3} \mathrm{Fe}_{0.07} \mathrm{Co}{ }_{0.2} \mathrm{Ce}_{0.43} \mathrm{O}_{\mathrm{x}} \mathrm{CV}$ reveals multiple oxidation processes that span a $0.2 \mathrm{~V}$ interval with redox onset at approximately $0.2 \mathrm{~V}$ lower potential than the $\mathrm{Ni}-\mathrm{Fe}$ sample $\left(\mathrm{Ni} 0.5 \mathrm{Fe} 0.5 \mathrm{O}_{\mathrm{x}}\right)$ and $0.1 \mathrm{~V}$ lower potential than the $\mathrm{Ni}-\mathrm{Co}$ sample $\left(\mathrm{Ni}_{0.57} \mathrm{Co}_{.43} \mathrm{O}_{\mathrm{x}}\right)$. These results, combined with the recently-documented spillover effect of nanocrystalline $\mathrm{CeO}_{2}$ in ORR catalysts, bring into question the chemical nature of the $\mathrm{Ni}, \mathrm{Fe}$ and $\mathrm{Co}$ in the active catalyst in the OER overpotential range of 0.3-0.4 V, in particular whether the addition of Ce results in the introduction of new (hydro)oxide species that give rise to its superior electrocatalytic performance at low overpotential and current density.

To directly probe the catalyst chemistry under these conditions, the $\mathrm{Ni}_{0.3} \mathrm{Fe}_{0.07} \mathrm{Co}_{0.2} \mathrm{Ce}_{0.43} \mathrm{O}_{\mathrm{x}}$ catalyst was studied under operando electrochemical conditions by means of "tender" X-ray (2-5 $\mathrm{keV}$ ) APXPS ${ }^{61,62}$ and hard X-ray (in the 5-9 keV range) XAS (using the fluorescence yield 
detection mode). The two techniques detect photoelectrons and fluoresced photons, respectively, leading to a different probed volume within the catalyst under operating conditions, as schematically reported in Figure 2. In the case of photoelectron detection, the probed volume is confined to the first $10 \mathrm{~nm}$ of the materials surface, with the sampling depth depending upon the kinetic energy of the incoming photons. The advantage of using 'tender' X-rays for the APXPS measurement is that the effective attenuation lengths (EAL) of the photoelectrons are much larger than with soft X-rays, enabling the study of sample surfaces buried by a nanometric-thick electrolyte layer, ${ }^{63}$ as schematically shown in Figure 2. On the other hand, using a photon inphoton out method with excitation energies within the hard X-ray regime enables the study of materials with a probe depth of several microns. Synergistic coupling of the two techniques yields complementary information about the surface chemistry (XPS) and the coordination shell structure of the elements distributed throughout the material (XAS).

It is also important to note the different electrochemical conditions investigated with operando APXPS and XAS. The physical arrangement of the APXPS experiment necessitates the use of lower current densities, ${ }^{64}$ which is well-suited for the study of $\mathrm{Ni}_{0.3} \mathrm{Fe}_{0.07} \mathrm{Co}_{0.2} \mathrm{Ce}_{0.43} \mathrm{O}_{\mathrm{x}}$ at low OER overpotential. For the operando XAS measurements, the sample is immersed in bulk electrolyte, enabling higher diffusion rates and electrocatalytic current densities, which is wellsuited for the study of $\mathrm{Ni}_{0.3} \mathrm{Fe}_{0.07} \mathrm{Co}_{0.2} \mathrm{Ce}_{0.43} \mathrm{O}_{\mathrm{x}}$ at an OER overpotential where its activity is comparable to that of Ni-Fe oxides. The combination of these techniques is a powerful approach for understanding the active catalyst species and the role of $\mathrm{Ce}$ in enhancing the activity at low overpotential.
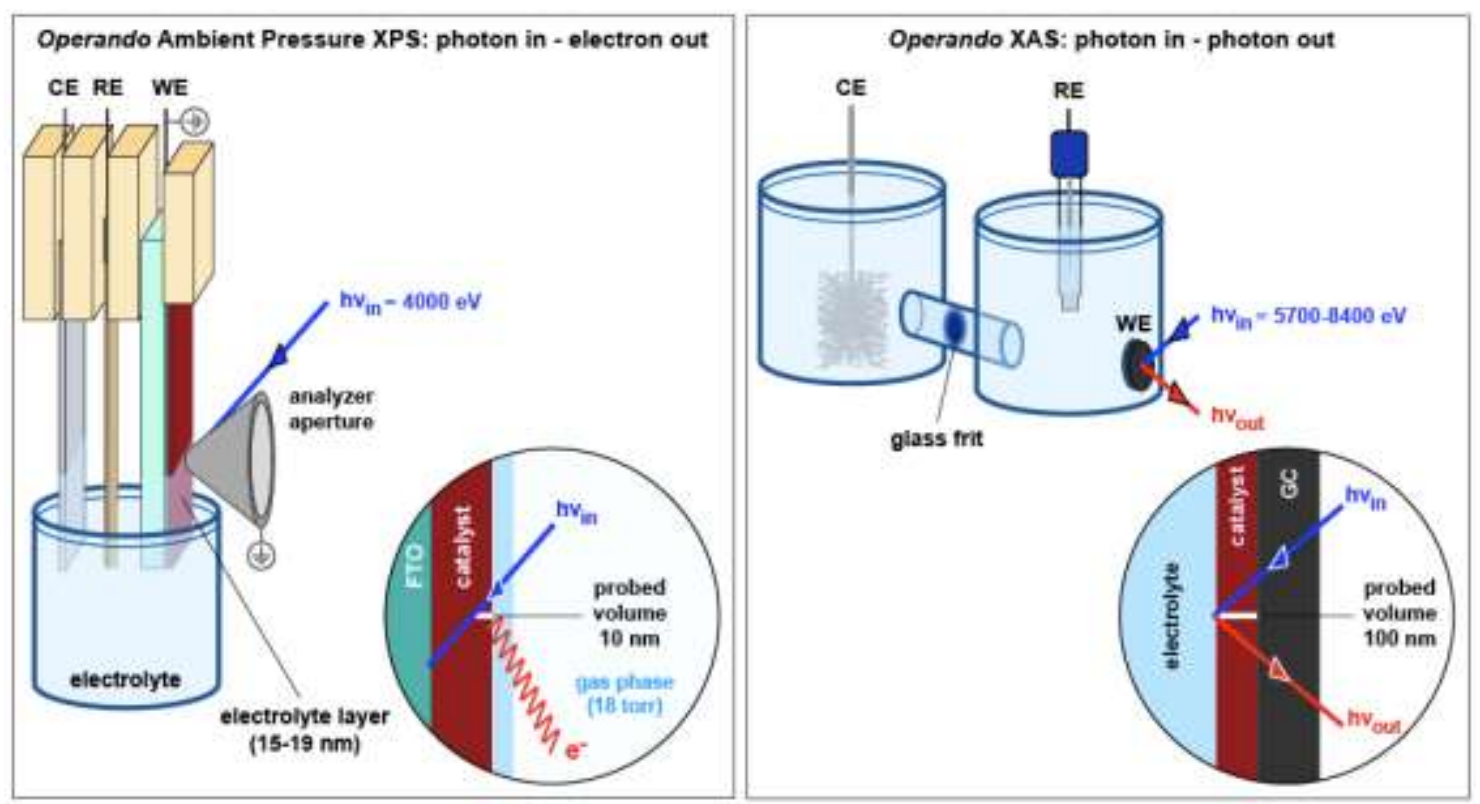

Figure 2. Schematic representation the APXPS and XAS setups, used in this work for the operando characterization of the quinary metal oxide OER electrocatalyst. The insets show the different detection mode of the two techniques and the corresponding probed volume. 
XPS has long been valuable for studying the surfaces of solids in vacuum by providing critical information regarding the composition and chemistry near the sample surface. ${ }^{65}$ Recent advances have extended the operational window of this technique from high vacuum conditions to higher pressures, enabling the examination of surfaces under operational and near-operational conditions. ${ }^{63}$ In this work, the surface of the electrocatalyst was studied after creating an electrolyte liquid layer, having a thickness between 15 and $19 \mathrm{~nm}$, by the 'dip and pull method'63 and characterized in the anodic regime up to and including the OER condition (hereafter labelled as "catalytic conditions"). The cyclic voltammetry and the corresponding chronoamperometry measurements are reported in Figures S1a, $\mathbf{b}$ and c. Previous studies, ${ }^{61,62}$ found that addition of 0.1 M KF to the 1.0 M KOH solution facilitated formation and stability of a stable solid/liquid interface. Since oxygen evolution in alkaline conditions consumes hydroxyls, the potential applied to the WE affects the stability of the nanometers-thick electrolyte layer. Keeping this potential constant, it has been found that adding $50-100 \mathrm{mM}$ of a supporting electrolyte enhances the stability of the solid/liquid interface. Comparison between Figures S1a and b indicates that the presence of KF does not appreciably influence the catalytic behavior of the quinary metal oxide catalyst, although higher current densities for the redox waves are observed. At these lower scan rates, the redox waves appear more symmetric than those observed in Figure 1d and are observed at comparable potentials. The OER operando condition for the APXPS was chosen to be $0.55 \mathrm{~V}$ vs $\mathrm{Ag} / \mathrm{AgCl}$, which corresponds to an OER overpotential of approximately $0.34 \mathrm{~V}$ and a current density slightly below $1 \mathrm{~mA} \mathrm{~cm}$. At this overpotential, the $\mathrm{Ni}_{0.3} \mathrm{Fe}_{0.07} \mathrm{Co}_{0.2} \mathrm{Ce}_{0.43} \mathrm{O}_{\mathrm{x}}$ was previously observed ${ }^{37}$ to exhibit 1.4 and $7.7 \mathrm{~mA} \mathrm{~cm}{ }^{-2}$ in scanning droplet cell and rotating disc electrode experiments (in $1 \mathrm{M} \mathrm{NaOH}$ ), respectively, indicating agreement in catalytic performance up to the variations in the mass transport properties of the cells. This potential exceeds that of the redox processes of $\mathrm{Ni}_{0.3} \mathrm{Fe}_{0.07} \mathrm{Co}_{0.2} \mathrm{Ce}_{0.43} \mathrm{O}_{\mathrm{x}}$ observed in Figures 1d and S1 such that the APXPS measurement captures the properties of the catalytically-active species at low overpotential.

Since the escaping photoelectrons can electrostatically interact with local fields, XPS provides information about the local potentials experienced by the atoms undergoing the photoionization process. ${ }^{65,66}$ By measuring the core level binding energy (BE) shift of the elements present in the liquid layer (e.g. O 1 s or $\mathrm{K} 2 \mathrm{p}$ peaks) as a function of the applied potential at the WE, it is possible to achieve full potential control at the solid/liquid interface and monitor the ion-supported electrical connection between the electrolyte layer on the sample surface and the bulk liquid phase, as reported in Figure S2a and b.

The photoelectron peaks of $\mathrm{Ce}, \mathrm{Ni}$ and $\mathrm{Co}$ are shown in Figure 3a, b and c, respectively, acquired in high vacuum ( $\mathrm{HV}, 10^{-6}$ torr), in the presence of water vapor (hydrated conditions, about 18 torr), and under electrochemical conditions, both at the open circuit potential (OCP, $0.125 \mathrm{~V}$ vs. $\mathrm{Ag} / \mathrm{AgCl} / \mathrm{Cl}^{-}$(sat.) $)$and at the selected OER overpotential (0.55 V vs. $\mathrm{Ag} / \mathrm{AgCl} / \mathrm{Cl}^{-}$ (sat.)). In the case of $\mathrm{Ce}$, the photoionization process involving the $3 d$ orbitals results in a rearrangement of the valence electrons. Due to the electrostatic interaction with the $3 d$ core hole, 
the localized $4 f$ levels undergo a downward shift below the Fermi level, so that hybridizations with the $\mathrm{O} 2 p$ band take place. Therefore the $\mathrm{Ce} 3 d$ orbitals, both in $\mathrm{Ce}^{(\mathrm{III})}{ }_{2} \mathrm{O}_{3}$ and $\mathrm{Ce}^{(\mathrm{IV})} \mathrm{O}_{2}$, are constituted by multiplets derived from the $4 f^{0}-4 f^{1}$ and pure $4 f^{1}$ final state configurations, respectively. The multipeak fitting procedure ${ }^{67-70}$ reported in Figure 3a indicates the presence of $\mathrm{Ce}(\mathrm{III})$ in the pristine sample (green shaded areas), which is partially re-oxidized upon exposure to water vapor (hydrated conditions), with the Ce(III) fraction decreasing from $19 \%$ to $11 \%$. The remaining $\mathrm{Ce}$ (III) is completely oxidized after dipping the WE into the electrolyte, as no $\mathrm{Ce}$ (III) can be detected in the OCP measurement. Furthermore, no further changes are observed to the Ce $3 d$ core level under catalytic conditions, confirming that the $\mathrm{CeO}_{2}$ nanoparticles observed in ex situ nanocharacterization experiments ${ }^{38}$ persist in the near-surface region under catalytic conditions.

The TM $2 p$ core levels pose a number of complications in the fitting procedure; specifically, shake-up, plasmon loss structures and multiplet splitting. The former are responsible for the generation of additional satellite peaks, ${ }^{71}$ usually characterized by a wide spectral broadening. On the other hand, multiplet splitting in the first-row TM arises from unpaired $d$ electrons in the valence band, and are usually associated with an oxygen-rich environment; in these instances, when a core electron vacancy is formed upon the photoionization process, there can be coupling between the unpaired $2 p$ electrons in the core with the unpaired outer shell $d$ electrons. ${ }^{71}$ This can create a number of different final states, which will manifest in the photoelectron spectrum through additional spectral features. Nonetheless, other many body processes influencing the core-hole lifetime can take place, such as Coster-Kronig transitions, which induce different fullwidth at half-maximum (FWHM) values of the $2 p_{3 / 2}$ and $2 p_{1 / 2}$ core level peaks. ${ }^{71,72}$ An additional complication arises from the fact that the studied material was prepared through a non-selective synthetic route; thus, different oxidation states and structures (including nano-sized crystallites ${ }^{38}$ ) are present at the surface, all contributing different amounts to the detected core levels. Finally, the energy resolution of the tender X-ray APXPS, about $0.3 \mathrm{eV}$, does not enable discrimination of spectral fine structures. For these reasons, we have developed an alternative fitting procedure. The Ni and Co $2 p_{3 / 2}$ peaks are first compared to literature reference spectra ${ }^{73}$ to isolate the main cation species responsible for the spectral line-shape. Then, the peaks are fit according to the literature procedure for the targeted cation. ${ }^{73}$ 

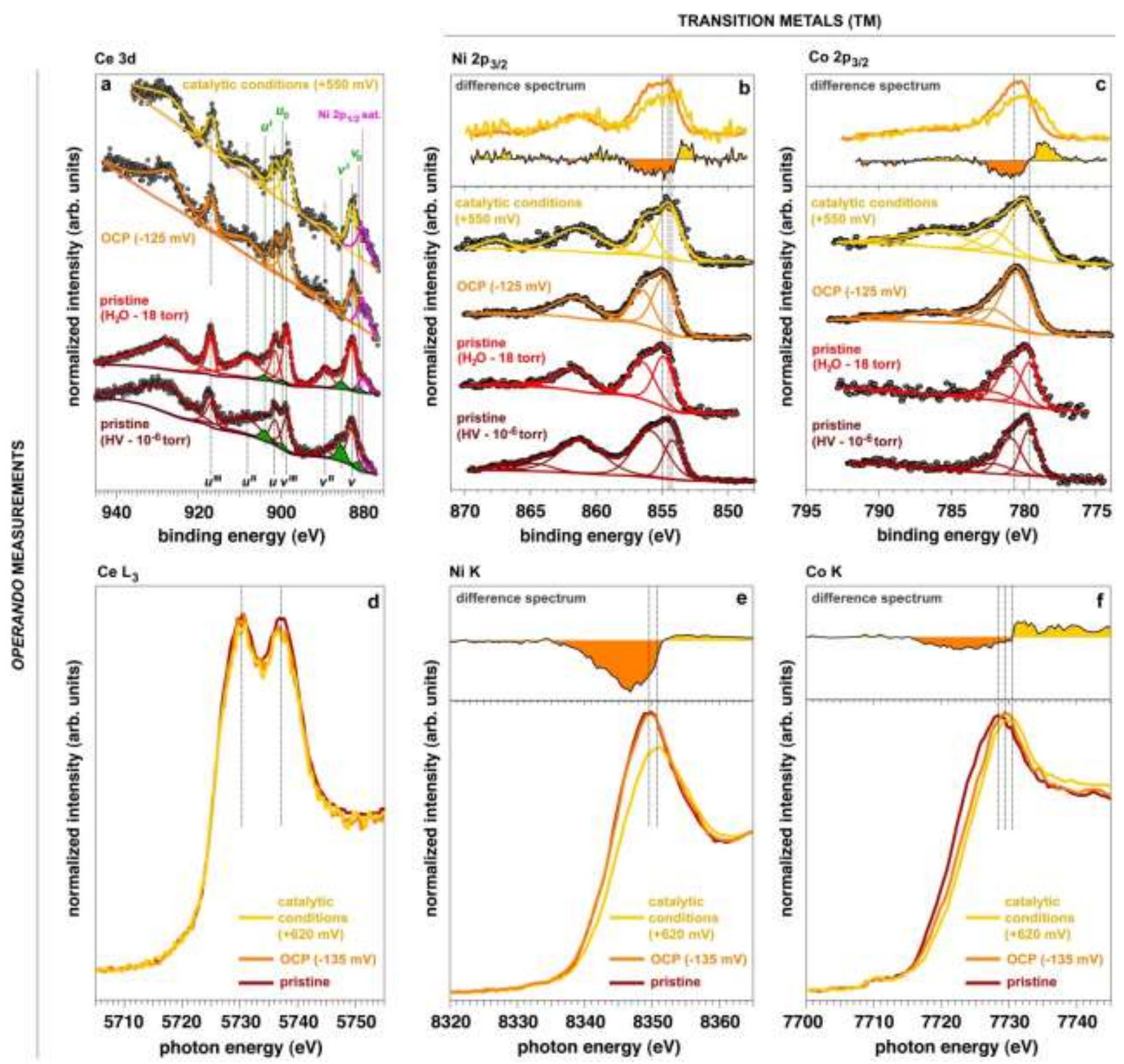

Figure 3. Top: operando APXPS at the Ce $3 d$ (a), Ni $2 p_{3 / 2}(\mathbf{b})$ and $\mathrm{Co} 2 p_{3 / 2}$ (c) photoelectron peaks acquired under different conditions (see text). To highlight the chemical changes in $\mathrm{Ni}$ and $\mathrm{Co}$, the top part of (b) and (c) reports the difference spectrum obtained by substracting the normalized peak acquired at the OCP from the normalized peak corresponding to the catalytic conditions. Bottom: operando XAS for the pristine quinary metal oxide catalyst, at the OCP and under catalytic conditions, at the $\mathrm{Ce}_{3}$ (d) and at the $\mathrm{Ni}(\mathbf{e})$ and $\mathrm{Co}$ (f) edges. The potentials are with respect to the $\mathrm{Ag} / \mathrm{AgCl}^{-} \mathrm{Cl}^{-}$(sat.) reference electrode.

As can be seen in Figure 3b, the Ni $2 p$ for the pristine material (analyzed in high vacuum) shows the typical line-shape of the rock salt $\mathrm{NiO}$ structure, with $\mathrm{Ni}$ present as $\mathrm{Ni}$ (II). ${ }^{73}$ Passing from the pristine material to the OCP conditions, the Ni $2 p_{3 / 2}$ peak undergoes a positive shift of about $0.7 \mathrm{eV}$. Moreover, an important decrease of the satellites centered at about $856 \mathrm{eV}$ and 861 $\mathrm{eV}$ takes place. These observations are consistent to the partial conversion of the $\mathrm{Ni}^{(\mathrm{II})} \mathrm{O}$ structure 
to $\mathrm{Ni}^{(\mathrm{II})}(\mathrm{OH})_{2}{ }^{74}$ Similarly to the reports for other Ni-based systems, ${ }^{54} \mathrm{Ni}$ undergoes a partial oxidative conversion from $\mathrm{Ni}(\mathrm{II})$ to $\mathrm{Ni}$ (III) as a consequence of the formation of the active $\mathrm{Ni}^{(\mathrm{III})} \mathrm{OOH}$ phase under catalytic conditions (oxygen evolution). This is substantiated by the slight decrease (about $0.4 \mathrm{eV}$ ) of the binding energy of the Ni $2 p_{3 / 2}$ peak from the OCP to the OER condition, ${ }^{74}$ clearly observed in the difference spectrum at the top of Figure $\mathbf{3 b}$. The complete conversion of the $\mathrm{Ni}^{(\mathrm{II})}(\mathrm{OH})_{2} / \mathrm{NiO}$ system into the $\mathrm{Ni}^{(\mathrm{III})} \mathrm{OOH}$ phase should involve different initial and final state configurations, leading to a different $\mathrm{Ni} 2 p$ shape (especially the $3 / 2$ spectral contribution), and the importance of the partial conversion to $\mathrm{Ni}^{(\mathrm{III})} \mathrm{OOH}$ is discussed further below. ${ }^{74}$

Co exhibits a progressive evolution from a mixed oxide $\left(\mathrm{Co}_{3} \mathrm{O}_{4}\right.$ or $\left.\mathrm{Co}^{(\mathrm{II})} \mathrm{O} \cdot \mathrm{Co}^{(\mathrm{III})}{ }_{2} \mathrm{O}_{3}\right)$ in the pristine material to a mainly $\mathrm{Co}^{(\mathrm{II})}(\mathrm{OH})_{2}$ structure $^{73}$ at the $\mathrm{OCP}$, as substantiated by the positive BE shift of the overall peak (by about $0.7 \mathrm{eV}$ ) and the important increase of the Co(II) shake up satellite at about $786 \mathrm{eV} .^{75}$ This partial reductive conversion is usually ascribed to hydroxylation of the outer surface, due to the high concentration of hydroxyls in the electrolyte. Interestingly, at $+550 \mathrm{mV}$ vs. $\mathrm{Ag} / \mathrm{AgCl} / \mathrm{Cl}^{-}$(sat.) the $2 p_{3 / 2}$ undergoes a downward $\mathrm{BE}$ shift, which is accompanied by significant spectral broadening. These changes are a clear fingerprint of the partial oxidation of $\mathrm{Co}^{(\mathrm{II})}(\mathrm{OH})_{2}$ into a sub-stoichiometric cobalt oxyhydroxyde $\left(\mathrm{Co}^{(\mathrm{II}, \mathrm{III})} \mathrm{O}_{\mathrm{x}}(\mathrm{OH})_{\mathrm{y}}\right)$ species. $^{75}$ Previous studies of $\mathrm{Co}$ and Ni oxide-based materials have established a correlation between OER catalytic activity and the concomitant oxidation of $\mathrm{Co}^{(\mathrm{II})}$ and $\mathrm{Ni}^{\text {(II) }}$ to $\mathrm{Co}^{(\mathrm{III})}$ and $\mathrm{Ni}^{\text {(III) }}$, creating intrigue into the coexistience of these species in this low current density operation of $\mathrm{Ni}_{0.3} \mathrm{Fe}_{0.07} \mathrm{Co}_{0.2} \mathrm{Ce}_{0.43} \mathrm{O}_{x}$, which is discussed below. ${ }^{53-55}$

To further understand the active species in this complex oxide catalysts, we perform complementary XAS experiments, which probe transitions from core level electronic states to higher-energy unoccupied electronic states, showing sensitivity to oxidation state (similar to XPS), while also revealing details of the electronic structure of the material being observed. ${ }^{76}$ Additionally, the EXAFS region of the spectrum provides short-range $(<0.5 \mathrm{~nm})$ structural information, making XAS a suitable tool for probing the interplay between bonding environment and electronic structure. ${ }^{77,78}$ As discussed above, when using fluorescence detection the probed depth $(\sim 10 \mu \mathrm{m}$ when resonant at $7 \mathrm{keV})$ is significantly higher than XPS, allowing investigation of the bulk properties of the entire catalyst film. The operando electrochemical cells used in this study take advantage of this large probe depth by introducing the X-rays through the back of the catalyst, avoiding the requirement for a thin electrolyte layer and any subsequent limitations to the electrochemical current density. Therefore, operando XAS is used to determine the catalyst behavior at higher overpotential and current density. Figure S1 d, e, and $\mathbf{f}$ report the electrochemical characterization of the catalyst in $1.0 \mathrm{M} \mathrm{KOH}$ in the operando XAS cell, which includes the demonstration of stable electrocatalytic current density of approximately $8 \mathrm{~mA} \mathrm{~cm}^{-2}$ at $0.62 \mathrm{~V}$ vs. $\mathrm{Ag} / \mathrm{AgCl} / \mathrm{Cl}^{-}$(sat.), in approximate agreement with the $10 \mathrm{~mA} \mathrm{~cm}{ }^{-2}$ previously observed in $1.0 \mathrm{M} \mathrm{NaOH}$ electrolyte. ${ }^{37}$ This OER overpotential of approximately $0.41 \mathrm{~V}$ was chosen as the catalytic condition for XAS measurements due to the previous observation of 
comparable OER activity of $\mathrm{Ni}_{0.3} \mathrm{Fe}_{0.07} \mathrm{Co}_{0.2} \mathrm{Ce}_{0.43} \mathrm{O}_{x}$ with optimal $\mathrm{Ni}-\mathrm{Fe}$ catalysts at this potential. $^{37}$

$\mathrm{Ce}_{2}$, Ni K and Co $\mathrm{K}$ edges are shown in Figure 3d, e, and $\mathbf{f}$, respectively, for the dry catalyst (pristine), at $\mathrm{OCP}\left(-135 \mathrm{mV}\right.$ vs. $\left.\mathrm{Ag} / \mathrm{AgCl} / \mathrm{Cl}^{-}{ }_{\text {(sat.) }}\right)$, and under catalytic conditions (+620 $\mathrm{mV}$ vs. $\mathrm{Ag} / \mathrm{AgCl} / \mathrm{Cl}^{-}$(sat.)). The $\mathrm{Ce}_{3}$ edge, shown in Figure 3d, remains constant under all measured conditions, thereby confirming that $\mathrm{Ce}$ is not redox active in the potential range under investigation and is present as $\mathrm{CeO}_{2}$ under catalytic conditions. ${ }^{79-81}$

$\mathrm{Ni}$ and Co, however, both show clear redox activity passing from the OCP to catalytic conditions. The Ni K edge spectra (Figure 3e) are nearly identical for the pristine sample and at the OCP with a $+1.65 \mathrm{eV}$ shift under catalytic conditions, indicating partial oxidative conversion from $\mathrm{Ni}^{(\mathrm{II})}$ to $\mathrm{Ni}^{\text {(III) }}$. Operando EXAFS measurements (see SI Figure $\mathbf{S 3}$ a, b) show a decrease in $\mathrm{Ni}-\mathrm{O}$ bond lengths of $\sim 0.19 \AA$ under catalytic conditions, consistent with Ni oxidation. The latter is significantly more pronounced than that observed by operando APXPS at low current density. This implies that at higher current densities, Ni becomes significantly more active in the quinary metal oxide catalyst and undergoes similar chemistry to $\mathrm{Ni}_{1-\mathrm{x}} \mathrm{Fe}_{\mathrm{x}}$ oxide catalysts under the same conditions. Friebel et al. ${ }^{54}$ have demonstrated that, in $\mathrm{Ni}_{1-\mathrm{x}} \mathrm{Fe}_{\mathrm{x}}$ oxide catalysts, Ni undergoes a complete oxidation to $\mathrm{Ni}$ (III) under catalytic conditions, while $\mathrm{Fe}$ (III) occupies octahedral sites with a short Fe-O bond distance. The effect of this compression is that $\mathrm{Fe}(\mathrm{III})$ centers hosted in the $\mathrm{Ni}^{(\mathrm{III})}{ }_{1-\mathrm{x}} \mathrm{Fe}^{(\mathrm{III})}{ }_{\mathrm{x}} \mathrm{O}(\mathrm{OH})$ structure become active toward water oxidation. ${ }^{54}$ It is likely that the quinary metal oxide catalyst displays a similar catalytic mechanism at high current density.

At the Co $\mathrm{K}$ edge, shown in Figure 3f, a positive shift of $+0.9 \mathrm{eV}$ is observed when immersing the sample in the electrolyte, implying that some $\mathrm{Co}$ (II) in the pristine sample is oxidized to $\mathrm{Co}$ (III) immediately, before any potential is applied. Under catalytic conditions, a further shift of $+0.6 \mathrm{eV}$ is observed, as Co undergoes the previously discussed oxidative conversion to $\mathrm{Co}$ (III). While operando EXAFS does not show clear peak shifts under applied potential, the increase of overall peak intensity suggests more uniform Co-O and Co-Co bond lengths under catalytic conditions. This can be explained by oxidation of the Co(II) fraction in the initial state to $\mathrm{Co}(\mathrm{III})$. Assuming a mixed oxide phase similar to $\mathrm{Co}_{3} \mathrm{O}_{4}$, the octahedral $\mathrm{Co}$ (III) sites should display longer $\mathrm{Co}-\mathrm{O}$ distances and shorter $\mathrm{Co}-\mathrm{X}(\mathrm{X}=\mathrm{Co}, \mathrm{Ni}, \mathrm{Fe})$ distances compared to tetrahedral $\mathrm{Co}$ (II) sites $^{82}$. The change in distribution of bond lengths upon oxidation manifests as an overall sharpening of the EXAFS peaks as well as a slight skew to longer distance for the Co-O peak near $0.144 \mathrm{~nm}$, and a slight skew towards shorter distance for the Co$\mathrm{X}$ peak near $0.240 \mathrm{~nm}$. The observed oxidation upon immersion in electrolyte is different from the behavior observed by operando APXPS, in which the starting $\mathrm{Co}_{2} \mathrm{O}_{3}$ or $\mathrm{Co}^{(\mathrm{II})} \mathrm{O} \mathrm{Co}^{(\mathrm{III})}{ }_{2} \mathrm{O}_{3}$ is partially reduced at the outer surface to $\mathrm{Co}^{(\mathrm{II})}(\mathrm{OH})_{2}$ upon immersion in the electrolyte. No evidence for $\mathrm{Co}^{(\mathrm{II})}(\mathrm{OH})_{2}$ is seen in the Co K edge XAS spectra, suggesting that this species is only formed in the outer surface layer of the film, while the bulk is likely still a mixed oxide $\mathrm{Co}^{(\mathrm{II})} \mathrm{O} \cdot \mathrm{Co}^{(\mathrm{III})}{ }_{2} \mathrm{O}_{3}$, with the $\mathrm{Co}(\mathrm{III})$ fraction increasing when immersed in electrolyte. Under catalytic conditions, however, the spectral shift is consistent with XPS results, which show 
partial oxidation to a final sub-stoichometric cobalt oxyhydroxide $\left(\mathrm{Co}^{(\mathrm{II}, \mathrm{III})} \mathrm{O}_{\mathrm{x}}(\mathrm{OH})_{\mathrm{y}}\right)$ species. In addition, a similar Co XANES shift has been observed in different cobalt-based electrocatalysts in literature between OCP and oxygen evolution conditions. ${ }^{56,82-85}$ This shift has been interpreted as the formation of a $\mathrm{Co}(\mathrm{IV})$ fraction at catalytic conditions, following a $\mathrm{Co}$ (II) $\rightarrow \mathrm{Co}$ (III) $\rightarrow$ Co(IV) redox scheme. The EXAFS spectrum collected under the catalytic condition (SI, Figure S3a) also resembles the one reported by Kanan et al. ${ }^{56}$

Therefore, we hypothesize the presence of a mixed configuration at the surface at high current densities $(\sim 8 \mathrm{~mA} \mathrm{~cm})^{-2}$, where we observe the partial oxidative conversion to cobalt oxyhydroxide $(\mathrm{Co}(\mathrm{II}) \rightarrow \mathrm{Co}(\mathrm{III}))$ and the presence of $\mathrm{Co}(\mathrm{IV})(\mathrm{Co}$ (III) $\rightarrow \mathrm{Co}(\mathrm{IV}))$ as an active species in the catalytic cycle. ${ }^{56,82-85}$ The relatively small spectral shift observed by XAS is consistent with conversion being limited to the near-surface region. On the other hand, at the lower current densities (up to $1 \mathrm{~mA} \mathrm{~cm}^{-2}$ ) probed by operando APXPS, the steady state concentration of $\mathrm{Co}(\mathrm{IV})$ seems to be below the detection limit.

Regarding the redox chemistry of $\mathrm{Fe}$, the small concentration of $\mathrm{Fe}$ in the catalyst and $\mathrm{Fe}$ contaminants homogeneously present in the glassy carbon substrate unfortunately precludes any observation of activity at the Fe sites via the Fe K edge XAS.

To characterize the reversibility of the observed redox processes, post mortem analysis of $\mathrm{Ni}_{0.3} \mathrm{Fe}_{0.07} \mathrm{Co}_{0.2} \mathrm{Ce}_{0.43} \mathrm{O}_{\mathrm{x}}$ was performed after 3 hours of OER electrocatalysis at about $1 \mathrm{~mA} \mathrm{~cm}^{-2}$ (see Figure S1c), using in situ APXPS and ex situ soft X-ray XAS (Figure 4). Soft X-ray XAS (photon energies $<2 \mathrm{keV}$ ) probes a complementary set of core level excitations, providing additional information about electronic and bonding environment, but lower penetration depths necessitate ultra-high vacuum conditions. This energy range gives access to the $\mathrm{L}_{2,3}$ and $\mathrm{M}_{4,5}$ edge spectra for $\mathrm{Fe}, \mathrm{Co}, \mathrm{Ni}$ and $\mathrm{Ce}$, respectively, which are highly sensitive to oxidation state, spin state, and coordination structure. ${ }^{86,87}$ All of these spectra are obtained using total electron yield (TEY) detection, which has a probe depth of only a few $\mathrm{nm}$ and is therefore directly comparable to XPS. ${ }^{88}$ By measuring both pristine samples and samples that have been subjected to the catalytic conditions, any changes to the electronic and atomic structure as a result of the catalytic chemistry can be observed.

The in situ APXPS survey scans (BE: 0-1000 eV) acquired on the pristine material and after catalytic conditions are reported in Figure $\mathbf{S 4}$, whereas the high resolution measurements of the elemental spectral regions of interest and the corresponding soft-X ray TEY edges are reported in Figure 4. The analysis of the Ce $3 d$ core level (Figure 4a) reveals that Ce remains exclusively as $\mathrm{Ce}(\mathrm{IV})$ in the common $\mathrm{CeO}_{2}$ fluorite structure in the post mortem catalyst. Ex situ Ce M and TM L edge spectra of the catalyst before and after electrochemistry are shown in Figure $\mathbf{4 e}$ and $\mathbf{4 f}, \mathbf{g}$, and $\mathbf{h}$, respectively. No significant spectral changes are observed at the Ce $\mathbf{M}_{4,5}$ edge, shown in Figure 4e, with the spectra for catalysts before and after electrochemistry both matching that of $\mathrm{Ce}^{(\mathrm{IV})} \mathrm{O}_{2}$. A small shoulder at $881.4 \mathrm{eV}$, however, may indicate a small amount of $\mathrm{Ce}^{(\mathrm{III})}$ in the pristine sample, ${ }^{89,90}$ as seen in the APXPS measurements., 
The observed redox states of $\mathrm{Ni}$ species in the operando measurements are found to be completely reversible, as $\mathrm{Ni}$ is present as $\mathrm{Ni}^{(\mathrm{II})} \mathrm{O}$ with no evidence for any $\mathrm{Ni}^{(\mathrm{III})}$ species in both the pristine and post mortem catalysts (Figure $4 \mathbf{b}$ and f) $){ }^{91}$ Regarding the chemistry of Co, from the XPS data reported in Figure $4 \mathbf{c}$ it is possible to observe the presence of $\mathrm{Co}^{(\mathrm{III})}(\mathrm{OH})_{2}$, but not of $\mathrm{Co}^{(\mathrm{III})} \mathrm{O}(\mathrm{OH})$, in the post mortem sample. ${ }^{75}$ The $\mathrm{Co} \mathrm{L}_{3}$ edge spectrum of the pristine catalyst, shown in Figure $\mathbf{4 g}$, is similar to that of the mixed oxide $\mathrm{Co}^{\text {(II, III) }}{ }_{3} \mathrm{O}_{4}$, but the increased intensity of the feature near $777.8 \mathrm{eV}$, as well as the appearance of a new feature near $776.3 \mathrm{eV}$, indicates a higher concentration of $\mathrm{Co}^{\text {(II) }} .^{92}$ After electrochemistry, these two features are futher increased in intensity, and the spectrum resembles that of $\mathrm{Co}^{(\mathrm{II})}(\mathrm{OH})_{2}$, indicating reversibility of the charge state in the electrochemical redox processes with retention of hydroxyls. For both $\mathrm{Ni}$ and $\mathrm{Co}$, the catalytically active species are labile, with $\mathrm{Ni}^{(\mathrm{III})} \mathrm{O}(\mathrm{OH})$ and $\mathrm{Co}^{(\mathrm{III})} \mathrm{O}(\mathrm{OH})$ observed exclusively under operando conditions.

Unlike other elements in the quinary metal oxide, the APXPS analysis of the minority Fe species is limited to the pristine and cycled material, because of its small concentration. The coupling between the low Fe content and the attenutation imposed by the liquid layer and the relatively high pressure environment (about 18 torr) for the ejected photoelectrons, precluded detection of $\mathrm{Fe}$ under operando conditions. Comparison of the $\mathrm{Fe} 2 p$ photoemission peaks for the pristine and cycled material reported in Figure 4d indicates that $\mathrm{Fe}$ underoges an oxidation from a mixed $\mathrm{Fe}_{3} \mathrm{O}_{4}\left(\mathrm{Fe}^{(\mathrm{II})} \mathrm{O} \cdot \mathrm{Fe}_{2}{ }^{(\mathrm{III})} \mathrm{O}_{3}\right)$ system to a mainly $\mathrm{Fe}(\mathrm{III})$-based structure. ${ }^{73} \mathrm{Fe}(\mathrm{III})$ is actually the main oxidation state of Fe in the cycled sample, as substantiated by the positive BE shift of the overall Fe $2 p$ peak (about $0.9 \mathrm{eV})^{93}$ and the significant increase of the doublets whose $3 / 2$ components are centered at about $710.4 \mathrm{eV}$ and $713.1 \mathrm{eV}$ (shadowed areas in Figure 4d). Unambiguous determination of the particular structure present at the surface is not possible, due to the spectral overlap of the different Fe(III) phases. From comparison with other reports, we hypothesize the presence of $\mathrm{Fe}(\mathrm{III})$ in $\mathrm{Ni}^{(\mathrm{III})}{ }_{1-\mathrm{x}} \mathrm{Fe}^{(\mathrm{III})}{ }_{\mathrm{x}} \mathrm{O}(\mathrm{OH}){ }^{54,93,94}$ and $\mathrm{Fe}_{2}{ }^{(\mathrm{III})} \mathrm{O}_{3}{ }^{95}$ resulting from re-structuring of the surface upon removal of the anodic potential. The Fe $\mathrm{L}_{3}$ edge spectrum of

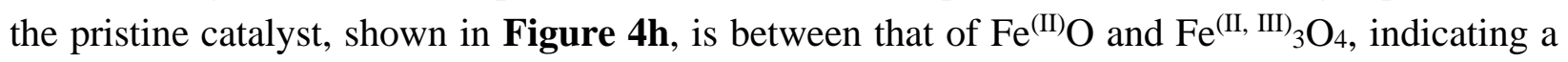
mixed oxide phase containing both $\mathrm{Fe}(\mathrm{II})$ and $\mathrm{Fe}(\mathrm{III}) .{ }^{96}$ After catalytic conditions, the spectrum is essentially unchanged. A slight sharpening of the feature near $708.3 \mathrm{eV}$ is consistent with an oxidation state of Fe(III) at the surface, as observed by in-situ APXPS. Unfortunately, the spectra of $\mathrm{Fe}(\mathrm{III})$ in different structural environments are nearly identical, ${ }^{96,97}$ making an exact determination of which species are present at the surface difficult. A mixture of $\mathrm{Fe}$ (III) in $\mathrm{Ni}^{(\mathrm{III})}{ }_{1 \text { - }}$ ${ }_{x} \mathrm{Fe}^{(\mathrm{IIII}}{ }_{\mathrm{x}} \mathrm{O}(\mathrm{OH})$ and $\mathrm{Fe}_{2}{ }^{(\mathrm{III})} \mathrm{O}_{3}$, as inferred from in situ APXPS, is likely. These observations agree with previous work conducted on Fe-Ni and Fe-Co based materials, where the Fe(III) species formed under operational conditions exhibit high activity for the OER, and it is worth noting that $\mathrm{Fe}(\mathrm{III})$ species form at lower potentials than the $\mathrm{Ni}$ and Co redox processes described above. ${ }^{93}$ 

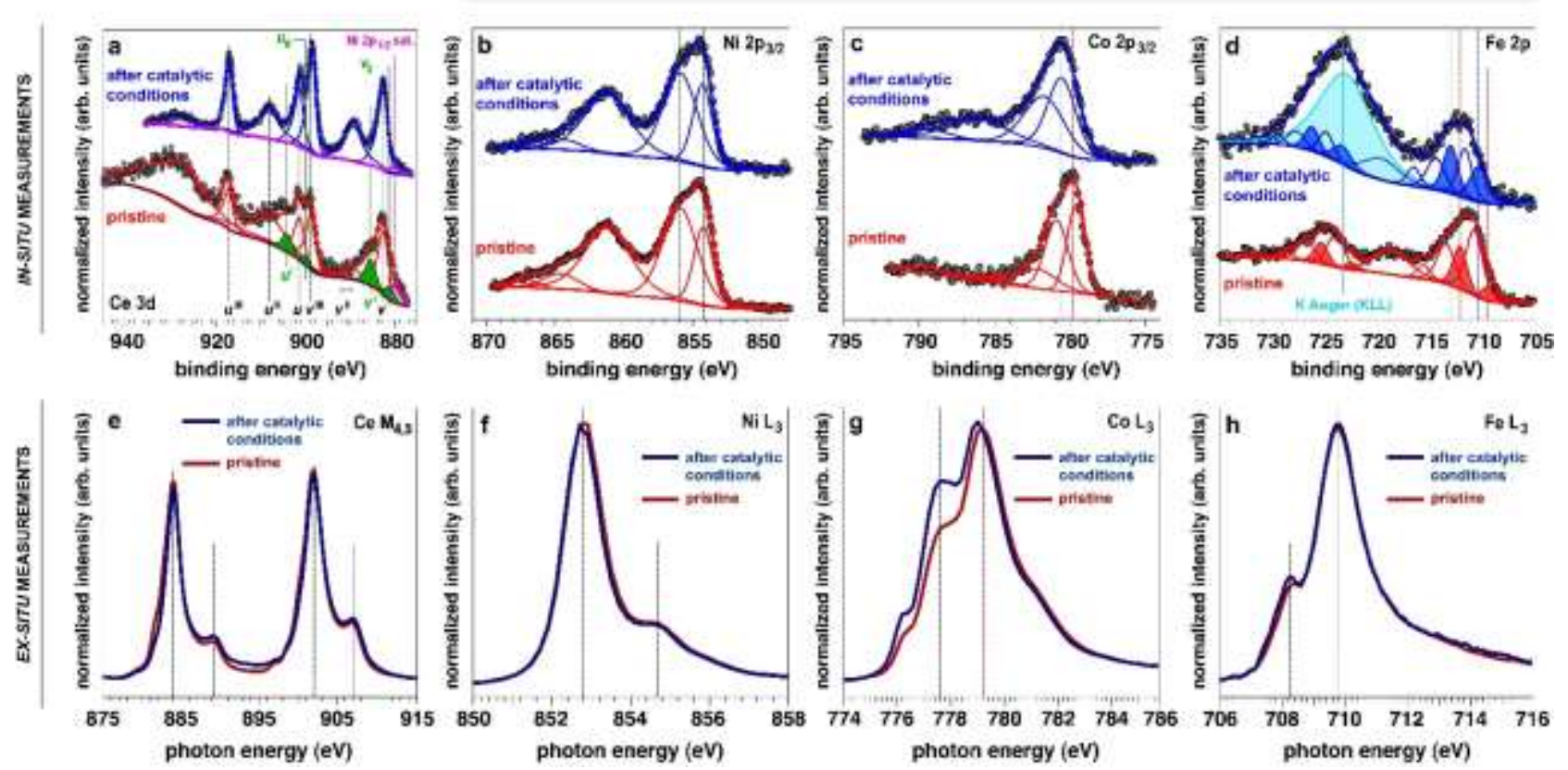

Figure 4. Top: in-situ APXPS of the pristine material and after catalytic conditions (performed at $4000 \mathrm{eV}$ and under hydrated conditions at a water vapor pressure between 16 and 18 torr); a: Ce $3 d$; b: Ni $2 p_{3 / 2} ; \mathbf{c}$ : Co $2 p_{3 / 2} ; \mathbf{d}$ : $\mathrm{Fe}$ 2p. Bottom: ex situ XAS of the pristine material and after catalytic conditions, at the $\mathrm{Ce}_{4,5}(\mathbf{e})$ and at the $\mathrm{Ni}(\mathbf{f})$, Co (g) and Fe K edges (h).

To gain further insight into the electronic properties of the quinary transition metal catalyst, the valence band (VB) XPS was acquired on the pristine material (hydrated conditions, 16 torr), under operando conditions (at the OCP and at $0.55 \mathrm{~V}$ vs. $\mathrm{Ag} / \mathrm{AgCl}^{-} \mathrm{Cl}^{-}$(sat.)) and "post mortem" after 3 hours of oxygen evolution (hydrated conditions, 16 torr). The results are reported in Figure 5.

The VB, as observed in Figures 5a, consists of three different regions, which can be identified by their position with respect to the Fermi level (normalized to zero via the tangent method and the calibration of $\mathrm{O} 2 s$, at around $23 \mathrm{eV}$ ). The first region, within the first $3 \mathrm{eV}$ below the Fermi level, is constituted by the density of states (DOS) at the upper edge of the VB. Typically these states are generated by low energy hybridizations of the metal valence shells (in this case, the $4 f$ from $\mathrm{Ce}$ and the $3 d$ from $\mathrm{Ni}, \mathrm{Co}$ and $\mathrm{Fe}$ ). The states that fall in this region are mainly responsible for the catalytic activity and electrical conductivity properties of the material, through their partial hybridization with states localized at the lower edge of the conduction band (CB) or localized states introduced in the energy band gap by a dopant. The second region, between 3 and $7 \mathrm{eV}$ below the Fermi level is typical of the metal oxides and, in this case, is generated by the hybridization of the $\mathrm{O} 2 p$ orbitals with the $\mathrm{Ce} 4 f$ and $\mathrm{Ni}, \mathrm{Co}, \mathrm{Fe} 3 d$ states. Finally, above $8 \mathrm{eV}$ hybridization between the $\mathrm{O} 2 p$ and $2 s$ shells from adsorbed and multilayer water on the surface occurs. ${ }^{98,99}$ 
In the first $\mathrm{VB}$ region of the pristine material and under operando OER conditions it is possible to observe the $\left(t_{2 \mathrm{~g}}\right)^{5}$ final state feature of $\mathrm{Co}(\mathrm{III})\left(d^{6}\right.$, centered at $1.5 \mathrm{eV}$ below the Fermi level), confirming the results discussed above about the core level photoemission of Co. ${ }^{75,100}$ This is also in line with the observations of Weidler et al. on Co-based electrocatalysts prepared using a CVD procedure. ${ }^{75}$ In agreement with the core level spectroscopy, the VB Co(III) feature is weaker at the OCP and post mortem conditions due to the partial reductive conversion of $\mathrm{Co}^{(\mathrm{II}, \mathrm{III})}{ }_{3} \mathrm{O}_{4}$ and $\mathrm{Co}^{(\mathrm{II}, \mathrm{III})} \mathrm{O}_{\mathrm{x}}(\mathrm{OH})_{\mathrm{y}}$ into $\mathrm{Co}^{(\mathrm{III})}(\mathrm{OH})_{2}$, respectively.

The partial oxidation of $\mathrm{Ni}$ and $\mathrm{Co}$ during the catalytic conditions is also confirmed by the analysis of the $\mathrm{O} 1 \mathrm{~s}$ photoelectron peak, reported in Figures $\mathbf{5 b}$ and $\mathbf{c}$ (specifically by the trend of the $\mathrm{TM}^{2-} \mathrm{O}^{2-}$ and $\mathrm{OH}$ components as a function of the different conditions). In particular, it is possible to observe that the hydroxyl component undergoes a negative shift by about $0.3 \mathrm{eV}$ when the material is under catalytic conditions. This is in agreement with other studies in literature, showing that the formation of the catalytic phases $\mathrm{Ni}^{(\mathrm{III})} \mathrm{O}(\mathrm{OH})$ and $\mathrm{Co}^{(\mathrm{III})} \mathrm{O}(\mathrm{OH})$ leads to a downward shift of the $\mathrm{OH} \mathrm{BE}$ component, as a result of the strong negative crystalline fields in the oxohydroxide trivalent $\mathrm{TM}$ compounds. ${ }^{75}$ Moreover, a full conversion from a $(\mathrm{Ni}, \mathrm{Co}, \mathrm{Fe})^{(\mathrm{II})}(\mathrm{OH})_{2}$ to a $(\mathrm{Ni}, \mathrm{Co}, \mathrm{Fe})^{(\mathrm{III})} \mathrm{O}(\mathrm{OH})$ phase should lead to a higher negative shift of the $\mathrm{OH}$ BE component $(\sim 1.1 \mathrm{eV})$ compared to that observed in this study. ${ }^{75}$ This observation is in line with the previous discussion regarding the partial oxidative conversion of $\mathrm{Ni}$ and $\mathrm{Co}$ at low overpotential/low current density operation $\left(0.55 \mathrm{~V}\right.$ vs $\mathrm{Ag} / \mathrm{AgCl} / \mathrm{Cl}^{-}$(sat.) and $\left.\sim 1 \mathrm{~mA} \mathrm{~cm}{ }^{-2}\right)$.

As noted above, complete oxidation of $\mathrm{Fe}$ into $\mathrm{Fe}(\mathrm{III})$ is expected at this potential, and given the high activity of $\mathrm{Fe}$ (III) species, ${ }^{93}$ its small concentration in the quinary oxide catalyst may play a role in optimization of OER activity. While the $\mathrm{CeO}_{2}$ may play a variety of roles in catalyst optimization, including structural scaffolding, the present work establishes perhaps its most important role in catalyst optimization. Its chemical influence on the other cations is revealed through the observations that $\mathrm{CeO}_{2}$ mediates the introduction of transition metal redox activity at low overpotential and that only a fraction of near-surface $\mathrm{Ni}$ and $\mathrm{Co}$ atoms are oxidizied into active $\mathrm{Ni}$ (III) and $\mathrm{Co}$ (III) species in the low overpotential catalyst operation where the quinary oxide was found to exhibit unique, superior activity. Table S2 includes a summary of the operando species observed in $\mathrm{Ni}_{0.3} \mathrm{Fe}_{0.07} \mathrm{Co}_{0.2} \mathrm{Ce}_{0.43} \mathrm{O}_{\mathrm{x}}$ with comparisons to literature reports on $\mathrm{Ni}$-, $\mathrm{Fe}$ and $\mathrm{Co}$-based catalysts. 

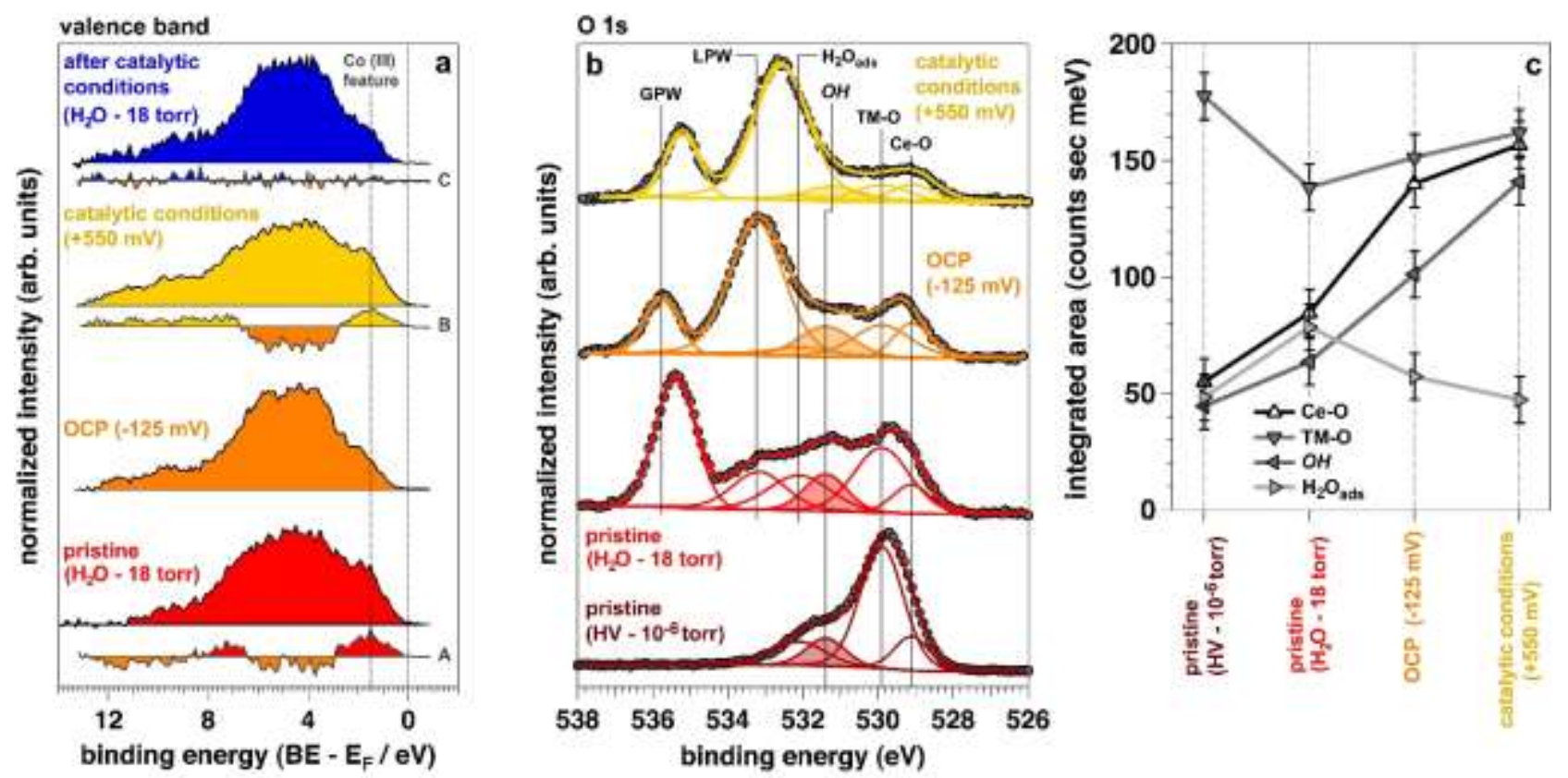

Figure 5. a: Background subtracted and area normalized valence band (VB) of the quinary metal oxide catalyst under operando and resting conditions, at a photon energy of $4000 \mathrm{eV}$. The difference spectra A, B and C have been obtained using the VB at OCP as reference; $\mathbf{b}$, $\mathbf{c}$ : Multipeak fitting procedure performed on the $\mathrm{O} 1 \mathrm{~s}$ peak (acquired at $4000 \mathrm{eV}$ ) and trend of the integrated areas of the fitting components as a function of the different investigated conditions, respectively. The fitting components were normalized for the effective attenuation length (EAL) of the liquid layer on the sample surface using the inverse Beer-Lambert relation. The potentials are with respect to the $\mathrm{Ag} / \mathrm{AgCl} / \mathrm{Cl}^{-}$(sat.) reference electrode.

\section{Conclusion}

The operando APXPS findings suggest that at low current densities the electrochemical performance of the quinary metal oxide is supported by $\mathrm{Ni}$, $\mathrm{Co}$ and $\mathrm{Fe}$, specifically on their electrochemical activation from a II oxidation state to active $(\mathrm{Ni}, \mathrm{Fe}, \mathrm{Co})^{(\mathrm{III})} \mathrm{O}(\mathrm{OH})$ species, albeit a partial oxidation in the case of $\mathrm{Ni}$ and $\mathrm{Co}$. The operando XAS results highlight similarities and differences in the catalytic mechanism under low $\left(\sim 1 \mathrm{~mA} / \mathrm{cm}^{2}\right)$ and high $\left(\sim 8 \mathrm{~mA} / \mathrm{cm}^{2}\right)$ current density regimes. While in situ and ex situ surface analyses demonstrate the presence of Fe(III) specieis both before and after catalyst operation, the redox activity of $\mathrm{Ni}$ and Co near the onset of catalytic activity is critical to catalyst operation and optimization. At high current density, $\mathrm{Ni}$ is highly active in the catalyst and is reversibly oxidized from $\mathrm{Ni}^{(\mathrm{II})} \mathrm{O}$ to $\mathrm{Ni}^{(\mathrm{III})} \mathrm{O}(\mathrm{OH})$ under catalytic conditions, as seen in similar $\mathrm{Ni}_{1-\mathrm{x}} \mathrm{Fe}_{\mathrm{x}}$ catalysts, whereas at low current density only limited amounts of $\mathrm{Ni}^{(\mathrm{III})} \mathrm{O}(\mathrm{OH})$ are detected by operando APXPS. The bulk behavior of Co in the catalyst is significantly different than that at the surface, displaying partial bulk oxidation from $\mathrm{Co}(\mathrm{II})$ to $\mathrm{Co}$ (III) upon immersion in the electrolyte, likely through changing composition of the mixed $\mathrm{Co}^{(\mathrm{II})} \mathrm{O} \cdot \mathrm{Co}^{(\mathrm{III})}{ }_{2} \mathrm{O}_{3}$ phase. The surface is actually reduced to $\mathrm{Co}^{(\mathrm{III})}(\mathrm{OH})_{2}$ upon immersion in the electrolyte and then partially oxidized to a sub-stoichiometric cobalt oxyhydroxyde 
$\left(\mathrm{Co}^{(\mathrm{II}, \mathrm{III})} \mathrm{O}_{\mathrm{x}}(\mathrm{OH})_{\mathrm{y}}\right)$ at low overpotential catalytic conditions with further oxidation observed at higher overpotential. At the higher overpotential this $\mathrm{Co}^{(\mathrm{III})} \mathrm{O}(\mathrm{OH})$ layer persists deep enough into the catalyst film to be observed by fluorescence yield XAS. In addition, at the explored current density $\left(\sim 8 \mathrm{~mA} \mathrm{~cm}^{-2}\right)$, our XAS results resemble the data reported in literature about the existence of $\mathrm{Co}(\mathrm{IV})$ as active centers in cobalt-based electrocatalysts for oxygen evolution.

As reported, a detailed analysis of the role of Fe on the overall catalyst performance could not be achieved in an operando fashion. On the other hand, ex situ investigations have shown that $\mathrm{Fe}$ is mainly present as $\mathrm{Fe}(\mathrm{III})$ after catalytic conditions. Therefore, we can conclude that $\mathrm{Fe}$ is activated in the material at the potentials explored in the work, most likely as Fe(III) hosted in octahedral sites in $\mathrm{Ni}^{(\mathrm{III})}{ }_{1-\mathrm{x}} \mathrm{Fe}^{(\mathrm{III})}{ }_{\mathrm{x}} \mathrm{O}(\mathrm{OH})$, as reported in literature for $\mathrm{Ni}_{1-\mathrm{x}} \mathrm{Fe}_{\mathrm{x}}$ catalysts. ${ }^{87}$

Although a detailed explanation of the catalytic mechanism involving the oxidation states of the TMs is still to be determined, our findings allow us to conclude that the TM oxyhydroxide phases are promoted under catalytic conditions, and synergistically cooperate to enable the observed high electroactivity of water oxidation. In particular, our study shows that the direct observation of the activated species and the differences between high and low overpotential operation are possible only under operando conditions, particularly because the redox chemistry of TMs is largely reversible.

These results reveal an indirect influence of $\mathrm{CeO}_{2}$ on catalytic activity wherein the active species are the same transition metal oxyhydroxides observed in Ce-free catalysts and form at lower overpotentials due to interactions with nanocrystalline $\mathrm{CeO}_{2}$. Given the partial conversion to these species at the low current density condition where $\mathrm{Ni}_{0.3} \mathrm{Fe}_{0.07} \mathrm{Co}{ }_{0.2} \mathrm{Ce}_{0.43} \mathrm{O}_{\mathrm{x}}$ exhibits uniquely high activity, the oxyhydroxide species may be limited to the $\mathrm{Ni}$ and Co atoms in close proximity to the $\mathrm{CeO}_{2}$, implying that the previously-observed atomically-sharp grain boundaries are an important factor in the performance of this complex oxide catalyst and in boosting the water oxidation kinetics. This proposed role of $\mathrm{CeO}_{2}$ is reminiscent of, and more subtle than, the spillover effect of Pt-based ORR electrocatalysts, indicating that nanocrystalline $\mathrm{CeO}_{2}$ may continue to be a critical component of optimized catalysts for both the ORR and OER.

Supporting Information (SI). Experimental details of samples preparation and synchrotron-based operando APXPS and XAS, electrochemical characterization of the $\mathrm{Ni}_{0.3} \mathrm{Fe}_{0.07} \mathrm{Co}_{0.2} \mathrm{Ce}_{0.43} \mathrm{O}_{\mathrm{x}}$ catalysts under operando APXPS and XAS experimental conditions, operando APXPS conductivity measurements of the nanometer thick electrolyte layer for operando APXPS experiments, operando EXAFS at the Co and $\mathrm{Ni} \mathrm{K}$ edges obtained under catalytic conditions, in situ APXPS survey scans for the qualitative identification of the surface chemistry of the $\mathrm{Ni}_{0.3} \mathrm{Fe}_{0.07} \mathrm{Co}_{0 .} \mathrm{Ce}_{0.43} \mathrm{O}_{\mathrm{x}}$ catalyst before and after catalytic conditions, comparative table reporting the results obtained in this work together with previous literature findings. 


\section{Acknowledgment}

We thank Dan Guevarra for his assistance collecting the cyclic voltamograms shown in Figure 1, using the scanning drop electrochemical cell. This material is based upon work performed by the Joint Center for Artificial Photosynthesis, a DOE Energy Innovation Hub, supported through the Office of Science of the U.S. Department of Energy (Award No. DE-SC0004993). The XAS work was done at BL 10.3.2 at the Advanced Light Source, and at BL 7-3 at the Stanford Synchrotron Radiation Lightsource. The AP-XPS work was done at BL 9.3.1 at the Advanced Light Source. Use of the Stanford Synchrotron Radiation Lightsource, SLAC National Accelerator Laboratory, is supported by the U.S. Department of Energy, Office of Science, Office of Basic Energy Sciences under Contract No. DE-AC02-76SF00515. The Advanced Light Source is supported by the Director, Office of Science, Office of Basic Energy Sciences, of the U.S. Department of Energy under Contract No. DE-AC02-05CH11231. 


\section{References}

(1) Cook, T. R.; Dogutan, D. K.; Reece, S. Y.; Surendranath, Y.; Teets, T. S.; Nocera, D. G. Chem. Rev. 2010, 110, 6474-6502.

(2) Katsounaros, I.; Cherevko, S.; Zeradjanin, A. R.; Mayrhofer, K. J. J. Angew. Chem.-Int. Edit. 2014, 53, 102-121.

(3) Walter, M. G.; Warren, E. L.; McKone, J. R.; Boettcher, S. W.; Mi, Q. X.; Santori, E. A.; Lewis, N. S. Chem. Rev. 2010, 110, 6446-6473.

(4) Bell, A. T. Science 2003, 299, 1688-1691.

(5) Michalak, W. D.; Somorjai, G. A. Top. Catal. 2013, 56, 1611-1622.

(6) Schlogl, R.; Abd Hamid, S. B. Angew. Chem.-Int. Edit. 2004, 43, 1628-1637.

(7) Yoon, C.; Cocke, D. L. J. Non-Cryst. Solids 1986, 79, 217-245.

(8) May, K. J.; Carlton, C. E.; Stoerzinger, K. A.; Risch, M.; Suntivich, J.; Lee, Y. L.; Grimaud, A.; Shao-Horn, Y. J. Phys. Chem. Lett. 2012, 3, 3264-3270.

(9) Smith, R. D. L.; Prevot, M. S.; Fagan, R. D.; Zhang, Z. P.; Sedach, P. A.; Siu, M. K. J.; Trudel, S.; Berlinguette, C. P. Science 2013, 340, 60-63.

(10) Zhang, C.; Trudel, S.; Berlinguette, C. P. Eur. J. Inorg. Chem. 2014, 2014, 660664.

(11) Indra, A.; Menezes, P. W.; Sahraie, N. R.; Bergmann, A.; Das, C.; Tallarida, M.; Schmeißer, D.; Strasser, P.; Driess, M. J. Am. Chem. Soc. 2014,136, 17530-17536.

(12) Yang, Y.; Fei, H. L.; Ruan, G. D.; Xiang, C. S.; Tour, J. M. ACS Nano 2014, 8, 95189523.

(13) Iyer, A.; Del-Pilar, J.; King'ondu, C. K.; Kissel, E.; Garces, H. F.; Huang, H.; ElSawy, A. M.; Dutta, P. K.; Suib, S. L. J. Phys. Chem. C 2012, 116, 6474-6483.

(14) Kanan, M. W.; Nocera, D. G. Science 2008, 321, 1072-1075.

(15) Qiu, Y.; Xin, L.; Li, W. Z. Langmuir 2014, 30, 7893-7901.

(16) Chemelewski, W. D.; Lee, H.-C.; Lin, J.-F.; Bard, A. J.; Mullins, C. B. J. Am. Chem. Soc. 2014, 136, 2843-2850.

(17) Muller, C. I.; Rauscher, T.; Schmidt, A.; Schubert, T.; Weissgarber, T.; Kieback, B.; Rontzsch, L. Inter. J. Hydrogen Energy 2014, 39, 8926-8937.

(18) Klingan, K.; Ringleb, F.; Zaharieva, I.; Heidkamp, J.; Chernev, P.; GonzalezFlores, D.; Risch, M.; Fischer, A.; Dau, H. ChemSusChem 2014, 7, 1301-1310.

(19) Pajonk, G. M. Appl. Catal. A-Gen. 2000, 202, 157-169.

(20) Weng, L. T.; Delmon, B. Appl. Catal. A-Gen. 1992, 81, 141-213.

(21) Conner, W. C.; Falconer, J. L. Chem. Rev. 1995, 95, 759-788.

(22) Corrigan, D. A.; Conell, R. S.; Fierro, C. A.; Scherson, D. A. J. Phys. Chem. 1987, 91, 5009-5011.

(23) Corrigan, D. A.; Bendert, R. M. J. Electrochem. Soc. 1989, 136, 723-728.

(24) Subbaraman, R.; Tripkovic, D.; Chang, K. C.; Strmcnik, D.; Paulikas, A. P.; Hirunsit, P.; Chan, M.; Greeley, J.; Stamenkovic, V.; Markovic, N. M. Nat. Mater. 2012, 11, 550-557.

(25) Lyons, M. E. G.; Doyle, R. L.; Fernandez, D.; Godwin, I. J.; Browne, M. P.; Rovetta, A. Electrochem. Commun. 2014, 45, 56-59.

(26) Lyons, M. E. G.; Doyle, R. L.; Fernandez, D.; Godwin, I. J.; Browne, M. P.; Rovetta, A. Electrochem. Commun. 2014, 45, 60-62.

(27) Dionigi, F.; Strasser, P. Adv. Energy Mater. 2016, 6, 1600621. 
(28) Corrigan, D. A. J. Electrochem. Soc. 1987, 134, 377-384.

(29) Smith, A. M.; Trotochaud, L.; Burke, M. S.; Boettcher, S. W. Chem. Commun. 2015, 51, 5261--5263.

(30) Trotochaud, L.; Boettcher, S. W. Scr. Mater. 2014, 74, 25-32.

(31) Trotochaud, L.; Young, S. L.; Ranney, J. K.; Boettcher, S. W. J. Am. Chem. Soc. 2014, 136, 6744-6753.

2433.

(32) Lin, F. D.; Bachman, B. F.; Boettcher, S. W. J. Phys. Chem. Lett. 2015, 6, 2427-

(33) Nellist, M. R.; Laskowski, F. A. L.; Lin, F. D.; Mills, T. J.; Boettcher, S. W. Acc. Chem. Res. 2016, 49, 733-740.

(34) Burke, M. S.; Enman, L. J.; Batchellor, A. S.; Zou, S. H.; Boettcher, S. W. Chem. Mater. 2015, 27, 7549-7558.

(35) Burke, M. S.; Zou, S. H.; Enman, L. J.; Kellon, J. E.; Gabor, C. A.; Pledger, E.; Boettcher, S. W. J. Phys. Chem. Lett. 2015, 6, 3737-3742.

(36) Enman, L. J.; Burke, M. S.; Batchellor, A. S.; Boettcher, S. W. ACS Catal. 2016, 6, 2416-2423.

(37) Haber, J. A.; Cai, Y.; Jung, S. H.; Xiang, C. X.; Mitrovic, S.; Jin, J.; Bell, A. T.; Gregoire, J. M. Energy Environ. Sci. 2014, 7, 682-688.

(38) Haber, J. A.; Anzenburg, E.; Yano, J.; Kisielowski, C.; Gregoire, J. M. Adv. Energy Mater. 2015, 5, 1402307.

(39) Haber, J. A.; Xiang, C.; Guevarra, D.; Jung, S.; Jin, J.; Gregoire, J. M. ChemElectroChem 2014, 1, 524-528.

(40) Cargnello, M.; Doan-Nguyen, V. V. T.; Gordon, T. R.; Diaz, R. E.; Stach, E. A.; Gorte, R. J.; Fornasiero, P.; Murray, C. B. Science 2013, 341, 771-773.

(41) Trovarelli, A. Catal. Rev.: Sci. Eng. 1996, 38, 439-520.

(42) Zafiris, G. S.; Gorte, R. J. J. Catal. 1993, 139, 561-567.

(43) Lee, W.; Jung, H. J.; Lee, M. H.; Kim, Y. B.; Park, J. S.; Sinclair, R.; Prinz, F. B. Adv. Funct. Mater. 2012, 22, 965-971.

(44) Vayssilov, G. N.; Lykhach, Y.; Migani, A.; Staudt, T.; Petrova, G. P.; Tsud, N.; Skala, T.; Bruix, A.; Illas, F.; Prince, K. C.; Matolin, V.; Neyman, K. M.; Libuda, J. Nat. Mater. 2011, 10, 310-315.

(45) Ng, J. W. D.; García-Melchor, M.; Bajdich, M.; Chakthranont, P.; Kirk, C.; Vojvodic, A.; Jaramillo, T. F. Nat. Energy 2016, 1, 16053.

(46) Kwon, K.; Lee, K. H.; Jin, S. A.; You, D. J.; Pak, C. Electrochem. Commun. 2011, $13,1067-1069$.

(47) Lim, D. H.; Lee, W. D.; Choi, D. H.; Kwon, H. H.; Lee, H. I. Electrochem. Commun. 2008, 10, 592-596.

(48) Lim, D. H.; Lee, W. D.; Choi, D. H.; Lee, H. I. Appl. Catal., B 2010, 94, 85-96.

(49) Yu, H. B.; Kim, J. H.; Lee, H. I.; Scibioh, M. A.; Lee, J.; Han, J.; Yoon, S. P.; Ha, H. Y. J. Power Sources 2005, 140, 59-65.

(50) Fugane, K.; Mori, T.; Ou, D. R.; Suzuki, A.; Yoshikawa, H.; Masuda, T.; Uosaki, K.; Yamashita, Y.; Ueda, S.; Kobayashi, K.; Okazaki, N.; Matolinova, I.; Matolin, V. Electrochimica Acta 2011, 56, 3874-3883.

(51) Masuda, T.; Fukumitsu, H.; Fugane, K.; Togasaki, H.; Matsumura, D.; Tamura, K.; Nishihata, Y.; Yoshikawa, H.; Kobayashi, K.; Mori, T.; Uosaki, K. J. Phys. Chem. C 2012, 116, 10098-10102. 
(52) Montini, T.; Melchionna, M.; Monai, M.; Fornasiero, P. Chem. Rev. 2016, 116, 5987-6041.

(53) Friebel, D.; Bajdich, M.; Yeo, B. S.; Louie, M. W.; Miller, D. J.; Casalongue, H. S.; Mbuga, F.; Weng, T. C.; Nordlund, D.; Sokaras, D.; Alonso-Mori, R.; Bell, A. T.; Nilsson, A. Phys. Chem. Chem. Phys. 2013, 15, 17460-17467.

(54) Friebel, D.; Louie, M. W.; Bajdich, M.; Sanwald, K. E.; Cai, Y.; Wise, A. M.; Cheng, M. J.; Sokaras, D.; Weng, T. C.; Alonso-Mori, R.; Davis, R. C.; Bargar, J. R.; Norskov, J. K.; Nilsson, A.; Bell, A. T. J. Am. Chem. Soc. 2015, 137, 1305-1313.

(56) Gul, S.; Ng, J. W. D.; Alonso-Mori, R.; Kern, J.; Sokaras, D.; Anzenberg, E.; Lassalle-Kaiser, B.; Gorlin, Y.; Weng, T. C.; Zwart, P. H.; Zhang, J. Z.; Bergmann, U.; Yachandra, V. K.; Jaramillo, T. F.; Yano, J. Phys. Chem. Chem. Phys. 2015, 17, 8901-8912.

(56) Kanan, M. W.; Yano, J.; Surendranath, Y.; Dinca, M.; Yachandra, V. K.; Nocera, D. G. J. Am. Chem. Soc. 2010, 132, 13692-13701.

(57) Yoshida, M.; Gon, N.; Maeda, S.; Mineo, T.; Nitta, K.; Kato, K.; Nitani, H.; Abe, H.; Uruga, T.; Kondoh, H. Chem. Lett. 2014, 43, 1725-1727.

(58) Yoshida, M.; Kondoh, H. Chem. Rec. 2014, 14, 806-818.

(59) Yoshida, M.; Yomogida, T.; Mineo, T.; Nitta, K.; Kato, K.; Masuda, T.; Nitani, H.; Abe, H.; Takakusagi, S.; Uruga, T.; Asakura, K.; Uosaki, K.; Kondoh, H. J. Phys. Chem. C 2014, $118,24302-24309$.

(60) Wang, D.; Zhou, J.; Hu, Y.; Yang, J.; Han, N.; Li, Y.; Sham, T.-K. J. Phys. Chem. C 2015, 119, 19573-19583.

(61) Lichterman, M. F.; Hu, S.; Richter, M. H.; Crumlin, E. J.; Axnanda, S.; Favaro, M.; Drisdell, W.; Hussain, Z.; Mayer, T.; Brunschwig, B. S.; Lewis, N. S.; Liu, Z.; Lewerenz, H. J. Energy Environ. Sci. 2015, 8, 2409-2416.

(62) Lichterman, M. F.; Richter, M. H.; Hu, S.; Crumlin, E. J.; Axnanda, S.; Favaro, M.; Drisdell, W.; Hussain, Z.; Brunschwig, B. S.; Lewis, N. S.; Liu, Z.; Lewerenz, H. J. J. Electrochem. Soc. 2016, 163, H139-H146.

(63) Axnanda, S.; Crumlin, E. J.; Mao, B. H.; Rani, S.; Chang, R.; Karlsson, P. G.; Edwards, M. O. M.; Lundqvist, M.; Moberg, R.; Ross, P.; Hussain, Z.; Liu, Z. Sci. Rep. 2015, 5, DOI: $10.1038 /$ srep09788.

(64) Lewerenz, H.-J.; Lichterman, M. F.; Richter, M. H.; Crumlin, E. J.; Hu, S.; Axnanda, S.; Favaro, M.; Drisdell, W.; Hussain, Z.; Brunschwig, B. S.; Liu, Z.; Nilsson, A.; Bell, A. T.; Lewis, N. S.; Friebel, D. Electrochimica Acta 2016, 211, 711-719.

(65) Fadley, C. S. J. Electron Spectrosc. Relat. Phenom. 2010, 178, 2-32.

(66) Starr, D. E.; Liu, Z.; Havecker, M.; Knop-Gericke, A.; Bluhm, H. Chem. Soc. Rev. 2013, 42, 5833-5857.

(67) Artiglia, L.; Agnoli, S.; Paganini, M. C.; Cattelan, M.; Granozzi, G. ACS Appl. Mater. Interfaces 2014, 6, 20130-20136.

(68) Luches, P.; Pagliuca, F.; Valeri, S. J. Phys. Chem. C 2011, 115, 10718-10726.

(69) Skala, T.; Sutara, F.; Prince, K. C.; Matolin, V. J. Electron Spectrosc. Relat. Phenom. 2009, 169, 20-25.

(70) Tsunekawa, S.; Fukuda, T.; Kasuya, A. Surf. Sci. 2000, 457, L437-L440.

(71) Becker, U.; Shirley, D. A.; 1996 ed.; Springer US: New York, 1996.

(72) Nyholm, R.; Martensson, N.; Lebugle, A.; Axelsson, U. J. Phys., F 1981, 11, 1727-1733. 
(73) Biesinger, M. C.; Payne, B. P.; Grosvenor, A. P.; Lau, L. W. M.; Gerson, A. R.; Smart, R. S. Applied Surface Science 2011, 257, 2717.

(74) Biesinger, M. C.; Lau, L. W. M.; Gerson, A. R.; Smart, R. S. C. Phys. Chem. Chem. Phys. 2012, 14, 2434-2442.

(75) Weidler, N.; Paulus, S.; Schuch, J.; Klett, J.; Hoch, S.; Stenner, P.; Maljusch, A.; Brotz, J.; Wittich, C.; Kaiser, B.; Jaegermann, W. Phys. Chem. Chem. Phys. 2016, 18, 1070810718.

(76) Koningsberger, D.; Prins, R. X-ray absorption: principles, applications, techniques of EXAFS, SEXAFS, and XANES; John Wiley \& Sons: New York, 1988.

1986.

(77) Teo, B. K. EXAFS: Basic Principles and Data Analysis; Springer: New York,

(78) Koningsberger, D.; Mojet, B.; Van Dorssen, G.; Ramaker, D. Top. Catal. 2000, $10,143-155$.

(79) Shahin, A. M.; Grandjean, F.; Long, G. J.; Schuman, T. P. Chemistry of Materials 2005, 17, 315.

(80) Kaindl, G.; Schmiester, G.; Sampathkumaran, E. V.; Wachter, P. Phys. Rev. B 1988, 38, 10174-10177.

(81) Dexpert, H.; Karnatak, R. C.; Esteva, J. M.; Connerade, J. P.; Gasgnier, M.; Caro, P. E.; Albert, L. Phys. Rev. B 1987, 36, 1750-1753.

(82) McAlpin, J. G.; Surendranath, Y.; Dincă, M.; Stich, T. A.; Stoian, S. A.; Casey, W. H.; Nocera, D. G.; Britt, R. D. J. Am. Chem. Soc. 2010, 132, 6882-6883.

(83) Zhang, M.; de Respinis, M.; Frei, H. Nat. Chem. 2014, 6, 362-367.

(84) Risch, M.; Ringleb, F.; Kohlhoff, M.; Bogdanoff, P.; Chernev, P.; Zaharieva, I.; Dau, H. Energy Environ. Sci. 2015, 8, 661-674.

(85) Bergmann, A.; Martinez-Moreno, E.; Teschner, D.; Chernev, P.; Gliech, M.; de Araújo, J. F.; Reier, T.; Dau, H.; Strasser, P. Nat. Com. 2015, 6, 8625.

(86) de Groot, F. Chem. Rev. 2001, 101, 1779-1808.

(87) de Groot, F. M. F. J. Electron Spectrosc. Relat. Phenom.1994, 67, 529-622.

(88) Frazer, B. H.; Gilbert, B.; Sonderegger, B. R.; De Stasio, G. Surf. Sci. 2003, 537, 161-167.

(89) Smythe, D. J.; Brenan, J. M.; Bennett, N. R.; Regier, T.; Henderson, G. S. J. NonCryst. Solids 2013, 378, 258-264.

(90) Kundu, S.; Ciston, J.; Senanayake, S. D.; Arena, D. A.; Fujita, E.; Stacchiola, D.; Barrio, L.; Navarro, R. M.; Fierro, J. L. G.; Rodriguez, J. A. J. Phys. Chem. C 2012, 116, 1406214070.

(91) Wang, H.; Ge, P.; Riordan, C. G.; Brooker, S.; Woomer, C. G.; Collins, T.; Melendres, C. A.; Graudejus, O.; Bartlett, N.; Cramer, S. P. J. Phys. Chem. B 1998, 102, 83438346.

(92) Bora, D. K.; Cheng, X.; Kapilashrami, M.; Glans, P. A.; Luo, Y.; Guo, J.-H. J. Synchrotron Radiat. 2015, 22, 1450-1458.

(93) Klaus, S.; Louie, M. W.; Trotochaud, L.; Bell, A. T. J. Phys. Chem. C 2015, 119, 18303-18316.

(94) McIntyre, N. S.; Zetaruk, D. G. Anal. Chem. 1977, 49, 1521-1529.

(95) Ali-Loytty, H.; Louie, M. W.; Singh, M. R.; Li, L.; Casalongue, H. G. S.; Ogasawara, H.; Crumlin, E. J.; Liu, Z.; Bell, A. T.; Nilsson, A.; Friebel, D. J. Phys. Chem. C 2016, 120, 2247-2253. 
(96) Ahmed, F.; Kumar, S.; Arshi, N.; Anwar, M. S.; Heun Koo, B. CrystEngComm 2012, 14, 4016-4026.

(97) Chan, C. S.; De Stasio, G.; Welch, S. A.; Girasole, M.; Frazer, B. H.; Nesterova, M. V.; Fakra, S.; Banfield, J. F. Science 2004, 303, 1656-1658.

(98) Nishizawa, K.; Kurahashi, N.; Sekiguchi, K.; Mizuno, T.; Ogi, Y.; Horio, T.; Oura, M.; Kosugi, N.; Suzuki, T. Phys. Chem. Chem. Phys. 2011, 13, 413-417.

(99) Seidel, R.; Thurmer, S.; Winter, B. J. Phys. Chem. Lett. 2011, 2, 633-641.

(100) Langell, M. A.; Anderson, M. D.; Carson, G. A.; Peng, L.; Smith, S. Phys. Rev. B 1999, 59, 4791-4798. 


\section{Table of Contents Graphic:}

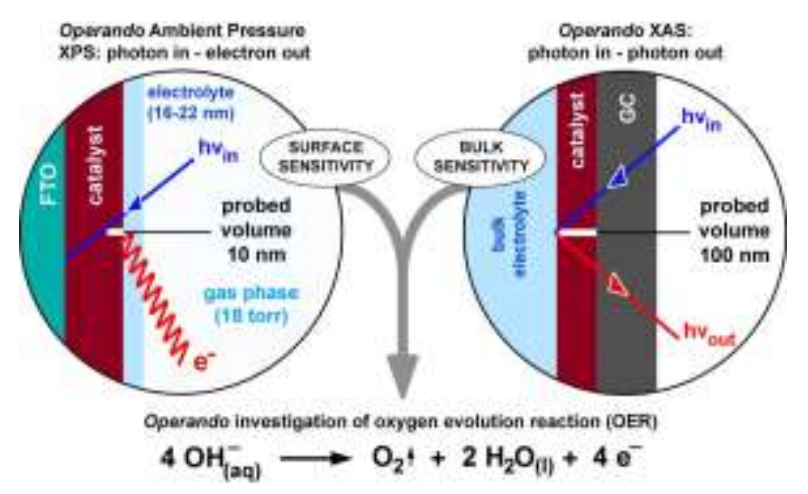

19

20

21

22

23

24

25

26

27

28

29

30

31

32

33

34

35

36

37

38

39

40

41

42

43

44

45

46

47

48

49

50

51

52

53

54

55

56

57

58

59

60 

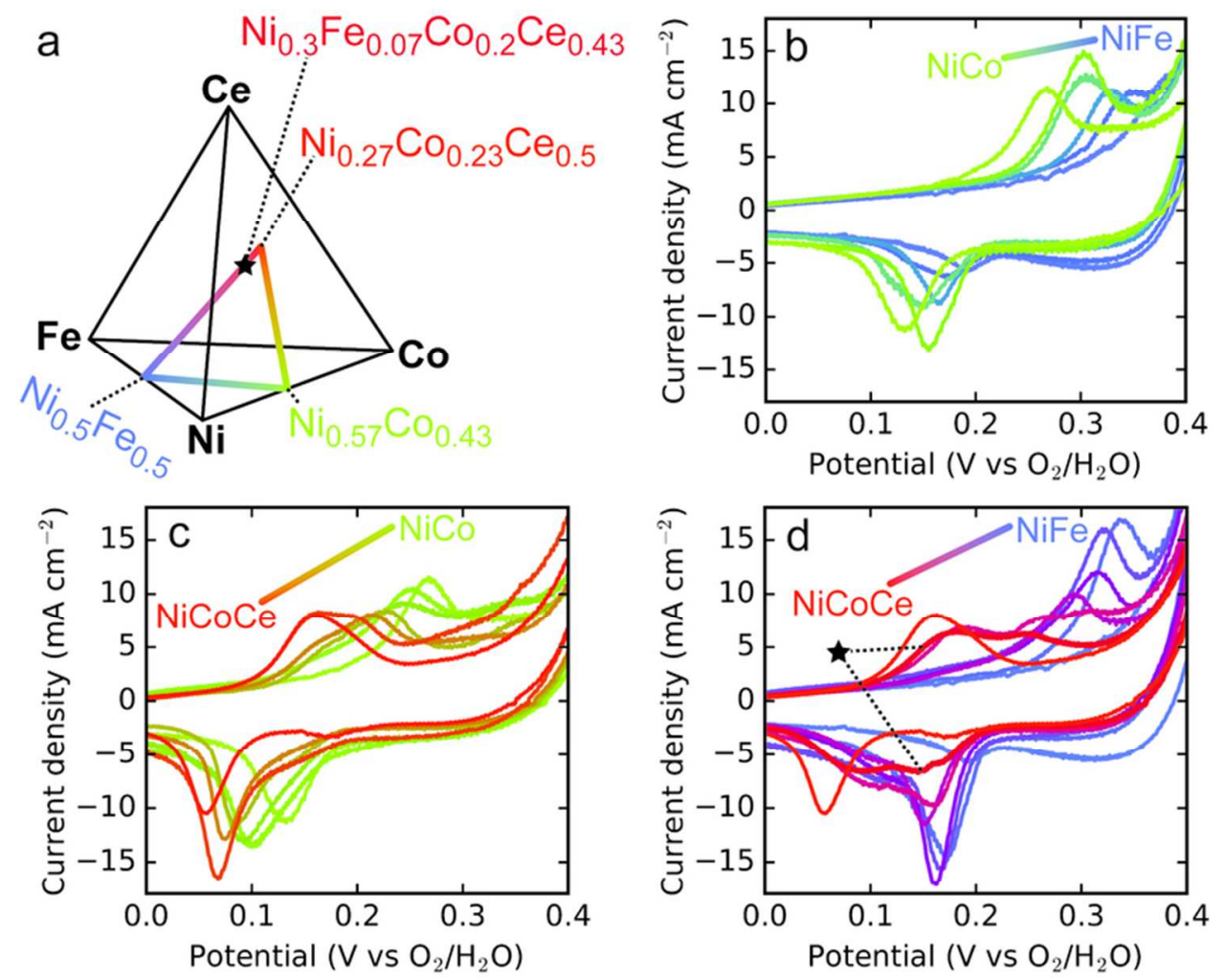

Figure 1. Color-coded composition lines in the Ni-Fe-Co-Ce oxide space (a) are shown with labelled endpoint compositions. The catalyst redox regions of CVs acquired at $0.25 \mathrm{~V} \mathrm{~s}-1$ are shown (b-d) for a series of compositions along each of the composition lines, with the Ni0.3Fe0.07Co0.2Ce0.430x catalyst noted by a star in $a$ and $d$. The high current density from the non-catalytic processes obscure the onset of OER electrocatalysis. The composition of each catalyst is provided in Table S1.

$74 \times 63 \mathrm{~mm}(300 \times 300 \mathrm{DPI})$ 
1

2

3

4

5

6

7

8

9

10

11

12

13

14

15

16

17

18

19

20

21

22

23

24

25

26

27

28

29

30

31

32

33

34

35

36

37

38

39

40

41

42

43

44

45

46

47

48

49

50

51

52

53

54

55

56

57

58

59

60

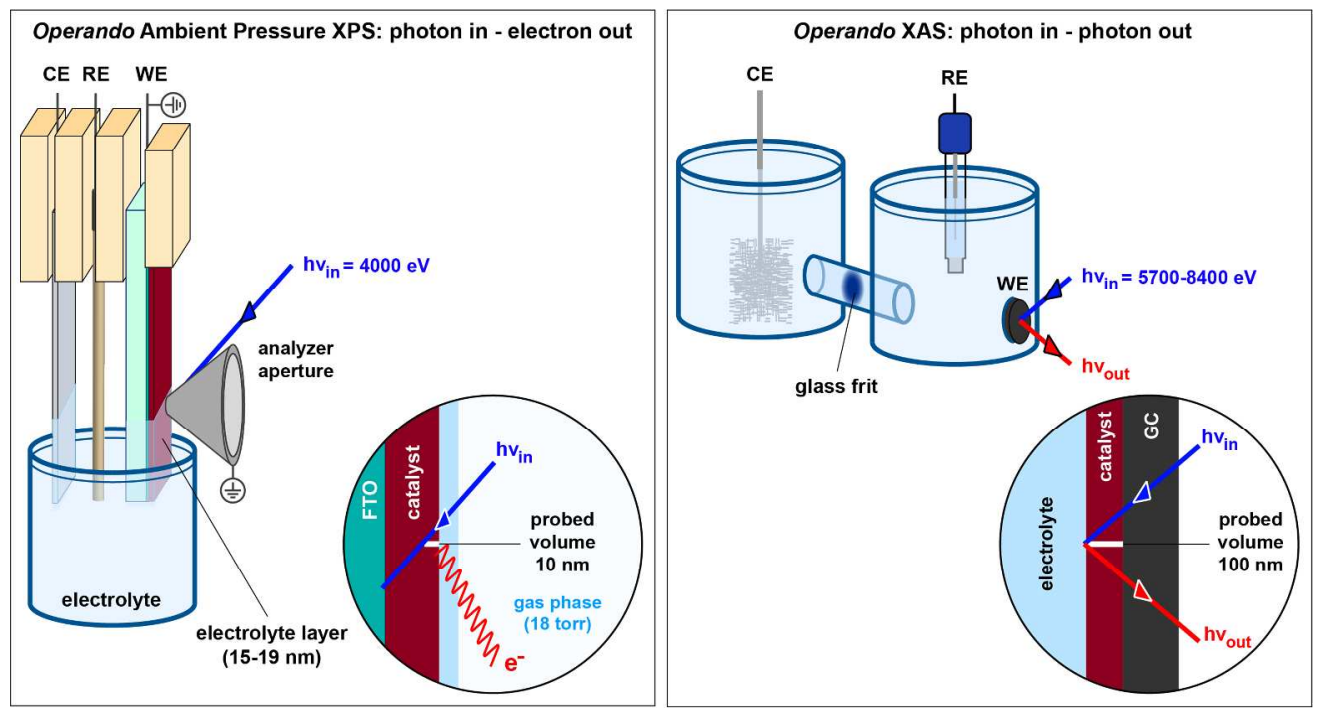

Figure 2. Schematic representation the APXPS and XAS setups, used in this work for the operando characterization of the quinary metal oxide OER electrocatalyst. The insets show the different detection mode of the two techniques and the corresponding probed volume.

$970 \times 521 \mathrm{~mm}(72 \times 72 \mathrm{DPI})$ 

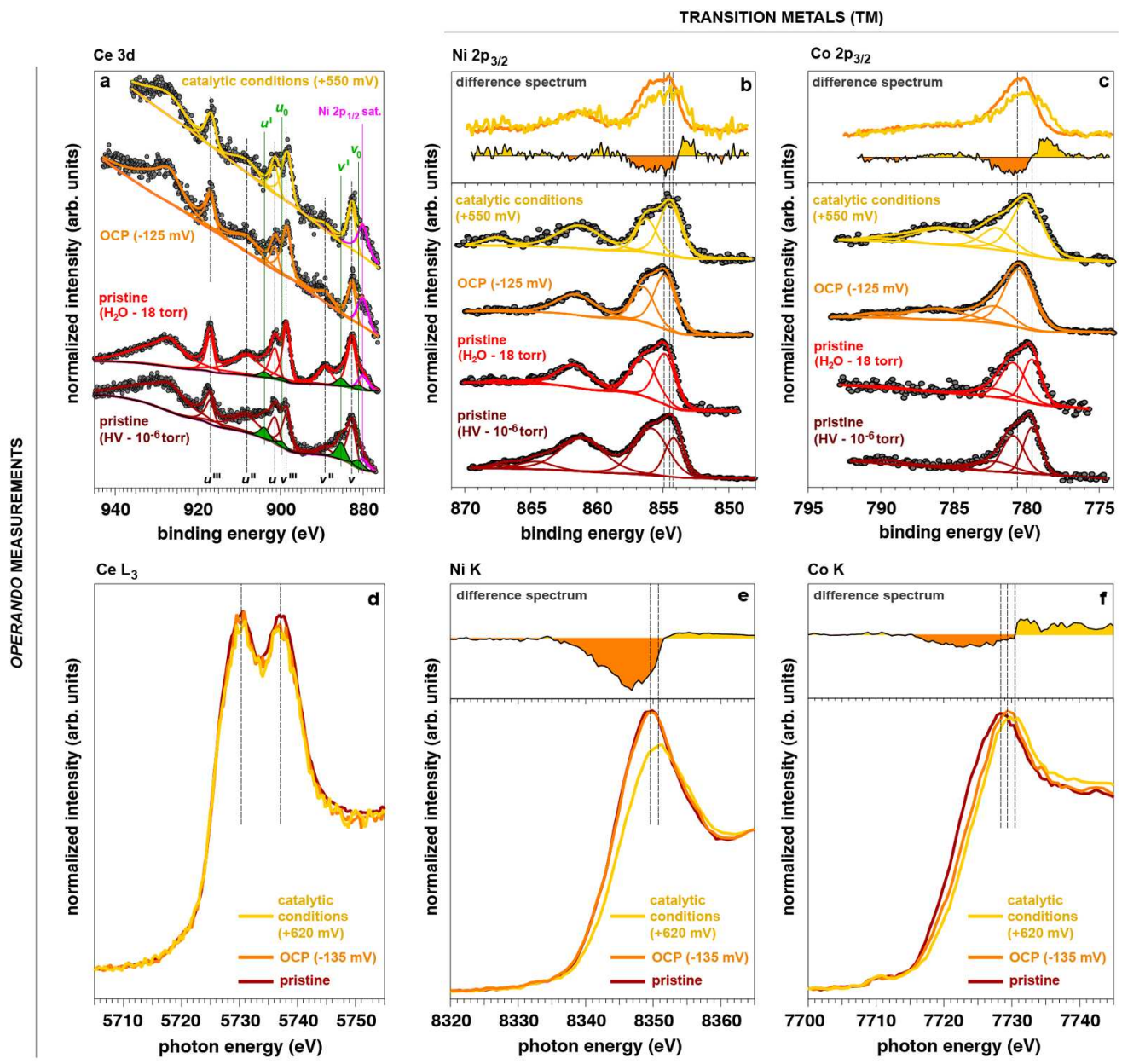

Figure 3. Top: operando APXPS at the Ce 3d (a), Ni 2p3/2 (b) and Co 2p3/2 (c) photoelectron peaks acquired under different conditions (see text). To highlight the chemical changes in $\mathrm{Ni}$ and $\mathrm{Co}$, the top part of (b) and (c) reports the difference spectrum obtained by substracting the normalized peak acquired at the OCP from the normalized peak corresponding to the catalytic conditions. Bottom: operando XAS for the pristine quinary metal oxide catalyst, at the OCP and under catalytic conditions, at the Ce L3 (d) and at the $\mathrm{Ni}(\mathrm{e})$ and $\mathrm{Co}(\mathrm{f})$ edges. The potentials are with respect to the $\mathrm{Ag} / \mathrm{AgCl} / \mathrm{Cl}$-(sat.) reference electrode. 
Figure 4. Top: in-situ APXPS of the pristine material and after catalytic conditions (performed at $4000 \mathrm{eV}$ and under hydrated conditions at a water vapor pressure between 16 and 18 torr); a: Ce 3d; b: Ni 2p3/2; c: Co 2p3/2; d: Fe 2p. Bottom: ex situ XAS of the pristine material and after catalytic conditions, at the Ce M4,5 (e) and at the Ni (f), Co (g) and Fe K edges (h).

$891 \times 459 \mathrm{~mm}(72 \times 72$ DPI $)$ 

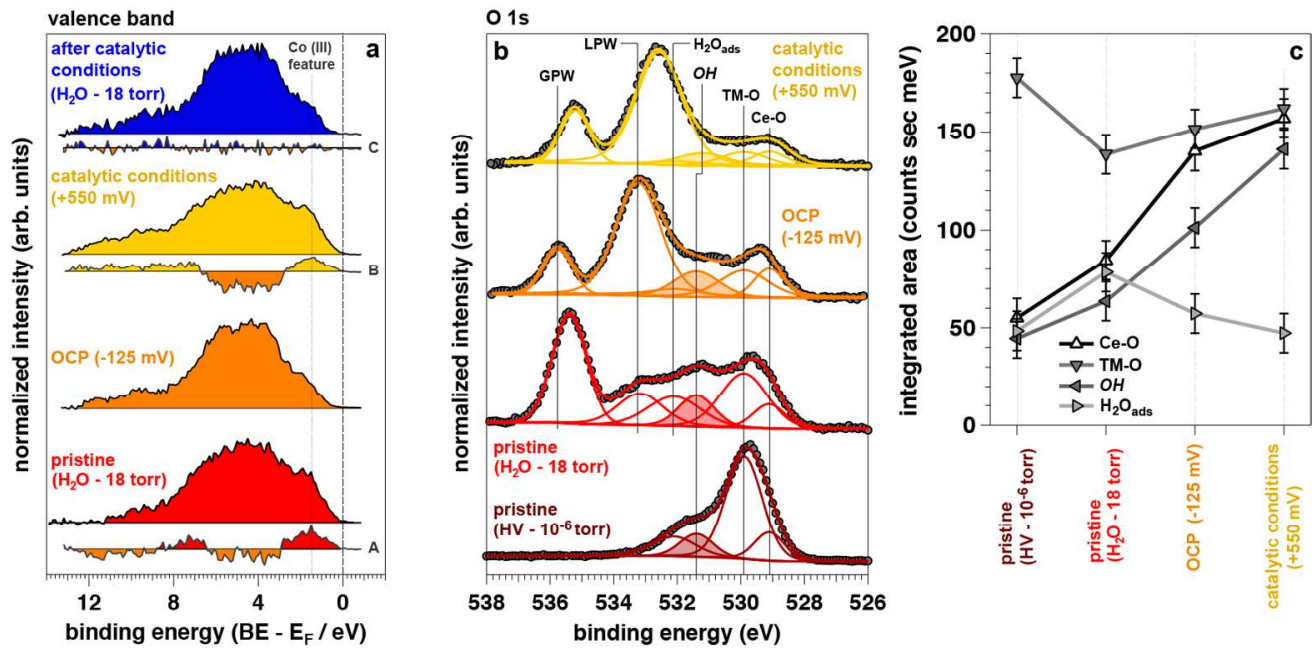

Figure 5. a: Background subtracted and area normalized valence band (VB) of the quinary metal oxide catalyst under operando and resting conditions, at a photon energy of $4000 \mathrm{eV}$. The difference spectra A, B and $C$ have been obtained using the VB at OCP as reference; b, c: Multipeak fitting procedure performed on the $\mathrm{O}$ 1s peak (acquired at $4000 \mathrm{eV}$ ) and trend of the integrated areas of the fitting components as a function of the different investigated conditions, respectively. The fitting components were normalized for the effective attenuation length (EAL) of the liquid layer on the sample surface using the inverse BeerLambert relation. The potentials are with respect to the $\mathrm{Ag} / \mathrm{AgCl} / \mathrm{Cl}$-(sat.) reference electrode.

$619 \times 308 \mathrm{~mm}(72 \times 72$ DPI $)$ 


1
2
3
4
5
6
7
8
9
10
11
12
13
14
15
16
17
18
19
20
21
22
23
24
25
26
27
28
29
30
31
32
33
34
35
36
37
38
39
40
41
42
43
40
45
49
50
50
51
53
55
50

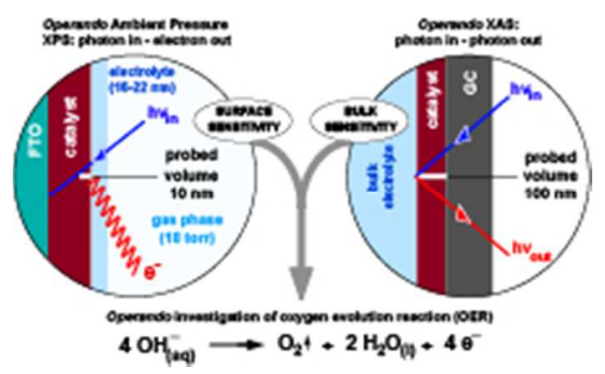

$78 \times 47 \mathrm{~mm}(72 \times 72$ DPI $)$ 